OAK RIDGE

NATIONAL LABORATORY

MANAGED BY UT-BATTELLE

FOR THE DEPARTMENT OF ENERGY

\title{
Quarterly Progress Report for the Chemical and Energy Research Section of the Chemical Technology Division: July-September 1999
}

\author{
R. T. Jubin
}




\title{
DOCUMENT AVAILABILITY
}

Reports produced after January 1,1996 , are generally available free via the U.S. Department of Energy (DOE) Information Bridge.

\section{Web site http://www.osti.gov/bridge}

Reports produced before January 1,1996 , may be purchased by members of the public from the following source.

\author{
National Technical Information Service \\ 5285 Port Royal Road \\ Springfield, VA 22161 \\ Telephone 703-605-6000 (1-800-553-6847) \\ TDD 703-487-4639 \\ Fax 703-605-6900 \\ E-mail info@ ntis.fedworld.gov \\ Web site http://www.ntis.gov/support/ordernowabout.htm
}

Reports are available to DOE employees, DOE contractors, Energy Technology Data Exchange (ETDE) representatives, and International Nuclear Information System (INIS) representatives from the following source.

Office of Scientific and Technical Information

P.O. Box 62

Oak Ridge, TN 37831

Telephone 865-576-8401

Fax 865-576-5728

E-mail reports@adonis.osti.gov

Web site http://www.osti.gov/contact.html

This report was prepared as an account of work sponsored by an agency of the United States Government. Neither the United States Government nor any agency thereof, nor any of their employees, makes any warranty, express or implied, or assumes any legal liability or responsibility for the accuracy, completeness, or usefulness of any information, apparatus, product, or process disclosed, or represents that its use would not infringe privately owned rights. Reference herein to any specific commercial product, process, or service by trade name, trademark, manufacturer, or otherwise, does not necessarily constitute or imply its endorsement, recommendation, or favoring by the United States Government or any agency thereof. The views and opinions of authors expressed herein do not necessarily state or reflect those of the United States Government or any agency thereof. 


\title{
Chemical Technology Division
}

\section{QUARTERLY PROGRESS REPORT FOR THE CHEMICAL AND ENERGY RESEARCH SECTION OF THE CHEMICAL TECHNOLOGY DIVISION: \\ JULY-SEPTEMBER 1999}

\author{
R. T. Jubin
}

Date Published-March 2001

\author{
Prepared by the \\ OAK RIDGE NATIONAL LABORATORY \\ Oak Ridge, Tennessee 37831-6285 \\ managed by \\ UT-BATTELLE, LLC \\ for the \\ U.S. DEPARTMENT OF ENERGY \\ under contract DE-AC05-00OR22725
}




\section{CONTENTS}

ACRONYMS AND ABBREVIATED FORMS $\ldots \ldots \ldots \ldots \ldots \ldots \ldots \ldots \ldots \ldots \ldots \ldots \ldots \ldots$

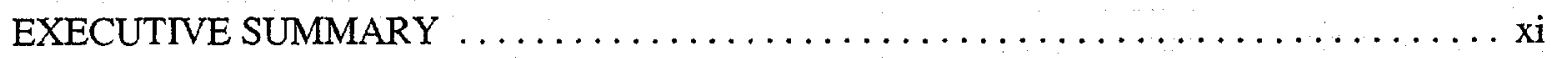

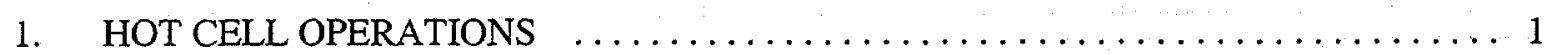

1.1 TESTING TWO CSTRS IN SERIES FOR THE SAVANNAH RIVER

SMALL-TANK TPB PRECIPITATION SIMULATION . . . . . . . . . . . 1

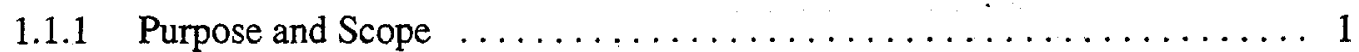

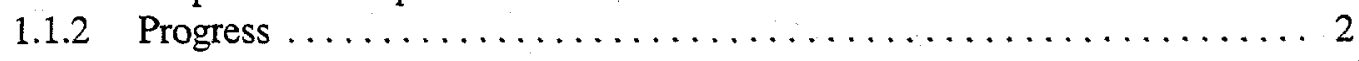

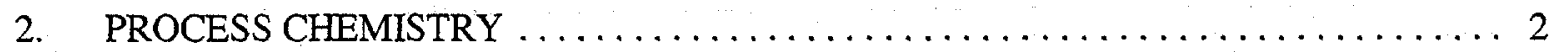

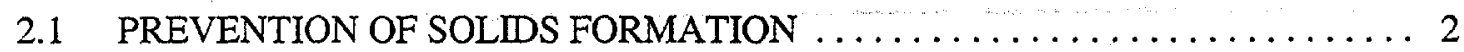

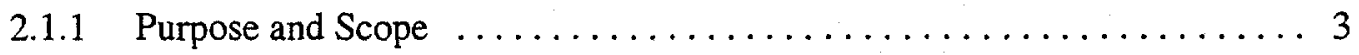

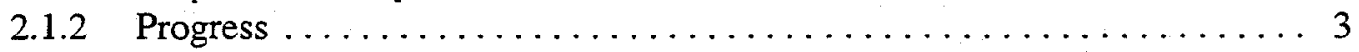

2.1.2.1 Viscosity Tests of Chemical Components in the Hanford Tank Waste (Task 3$) \ldots \ldots \ldots \ldots \ldots \ldots \ldots \ldots \ldots \ldots$

2.1.2.2 University Contest on Methods to Unplug a Plugged

Transfer Line (Task 4) ................. 4

2.1.2.3 Operating Envelopes (Task 4) $\ldots \ldots \ldots \ldots \ldots \ldots \ldots \ldots \ldots$

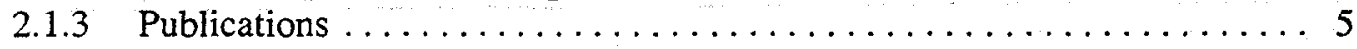

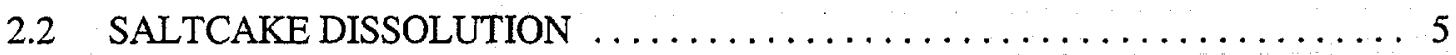

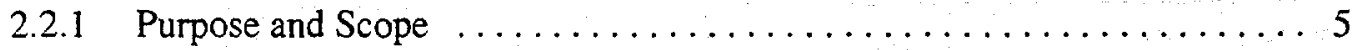

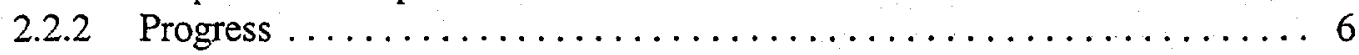

2.3 HANFORD SALTCAKE PREDICTIONS $\ldots \ldots \ldots \ldots \ldots \ldots \ldots \ldots \ldots \ldots \ldots$

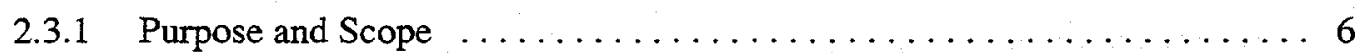

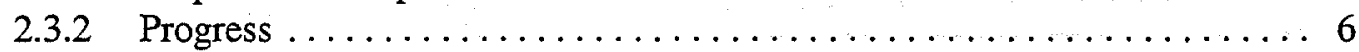

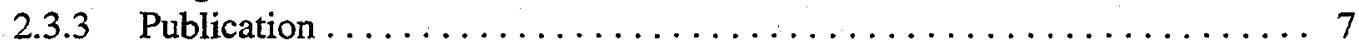

2.4 HYDROGEN DETECTION $\mathbb{I N}^{233} \mathrm{U}$ STORAGE WELLS $\ldots \ldots \ldots \ldots \ldots \ldots \ldots$

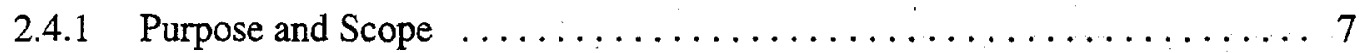

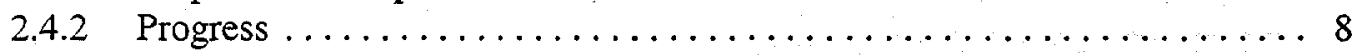

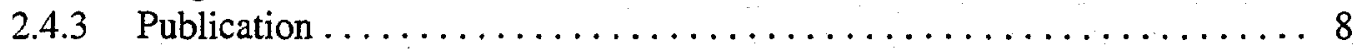

2.5 WAX FORMATION IN PETROLEUM MIXTURES $\ldots \ldots \ldots \ldots \ldots \ldots \ldots \ldots$

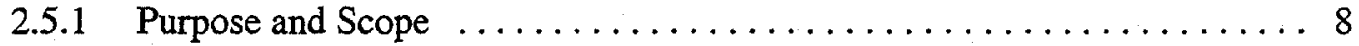

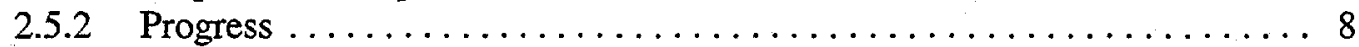

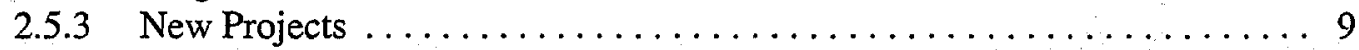

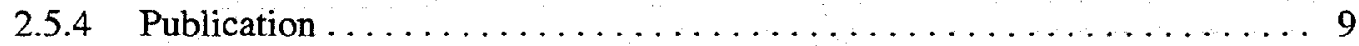

2.6 SPALLATION NEUTRON SOURCE SUPPORT $\ldots \ldots \ldots \ldots \ldots \ldots \ldots \ldots \ldots$

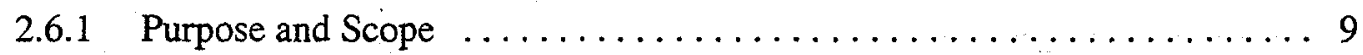

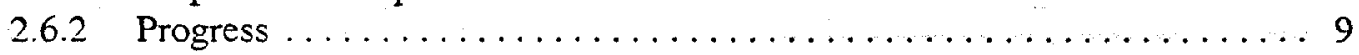

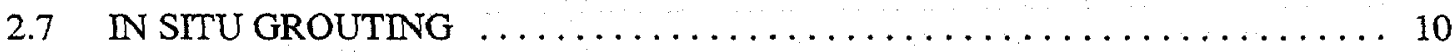

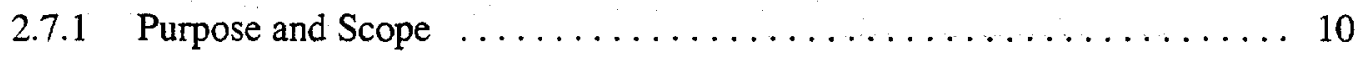




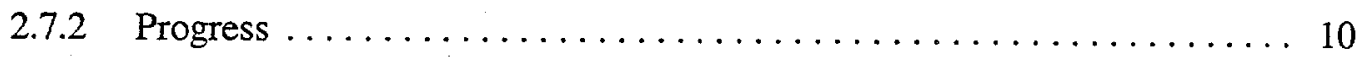

2.8 USEFUL CASTABLE DU SHAPES FOR THE DEPLETED

URANIUM ROADMAP $\ldots \ldots \ldots \ldots \ldots \ldots \ldots \ldots \ldots \ldots \ldots \ldots \ldots \ldots \ldots \ldots \ldots$

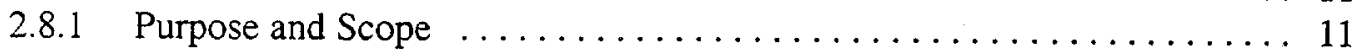

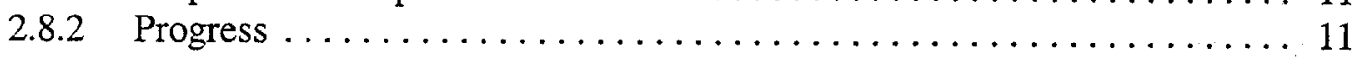

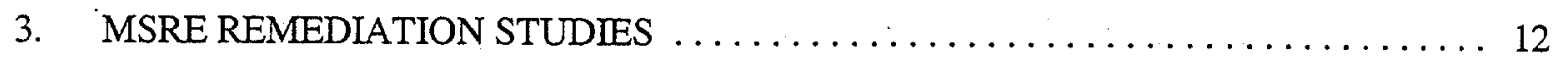

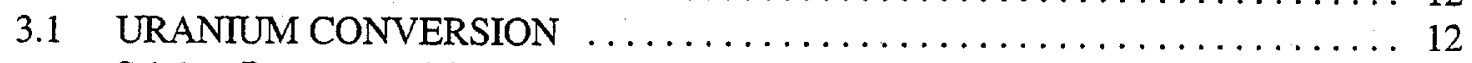

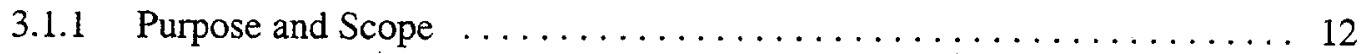

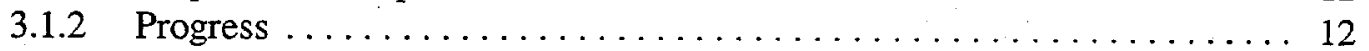

3.2 RADIOLYSIS AND MATERIALS DISPOSITION STUDIES $\ldots \ldots \ldots \ldots \ldots 13$

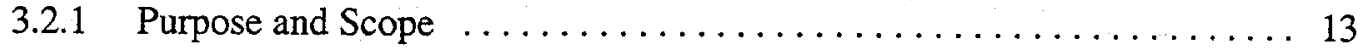

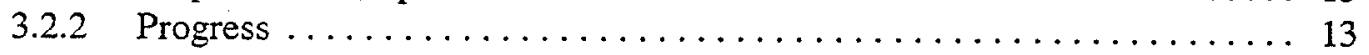

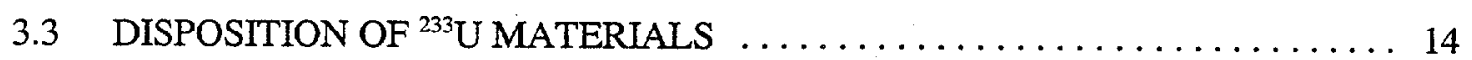

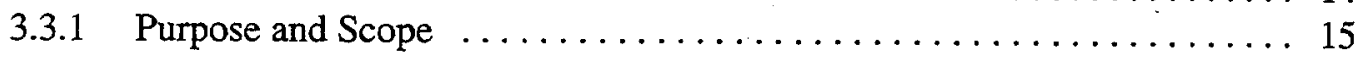

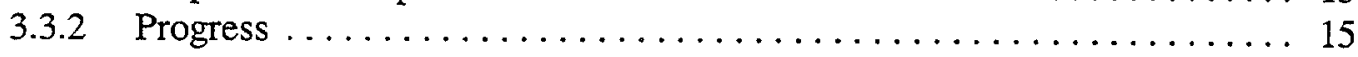

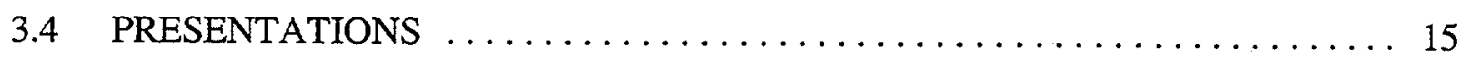

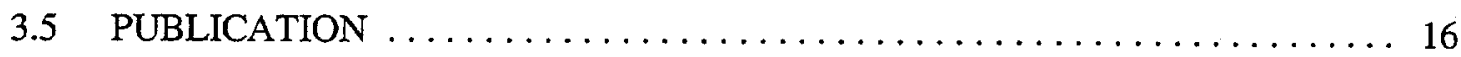

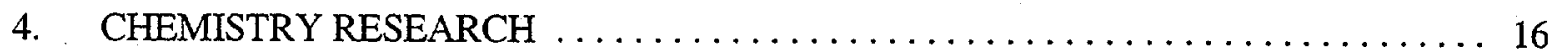

4.1 MOLECULAR IMPRINTING ON SOL-GEL MATRICES $\ldots \ldots \ldots \ldots \ldots \ldots$

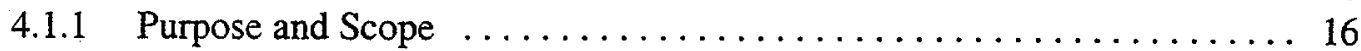

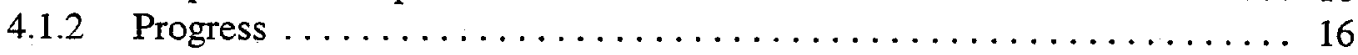

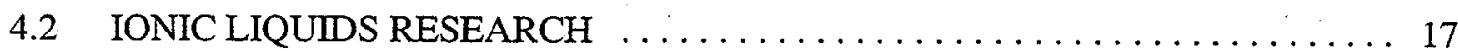

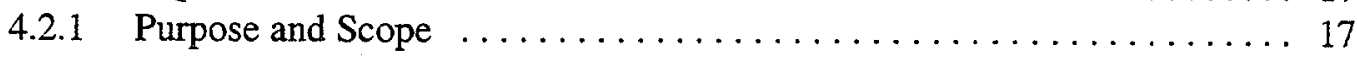

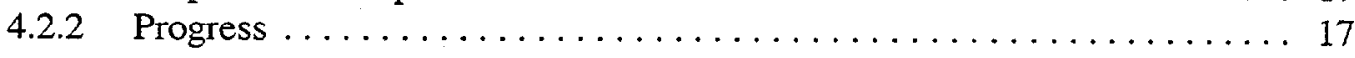

4.3 PUBLICATIONS $\ldots \ldots \ldots \ldots \ldots \ldots \ldots \ldots \ldots \ldots \ldots \ldots \ldots \ldots \ldots \ldots \ldots \ldots \ldots$

5. PHYSICAL PROPERTIES RESEARCH $\ldots \ldots \ldots \ldots \ldots \ldots \ldots \ldots \ldots \ldots \ldots \ldots$

5.1 PHYSICAL PROPERTY MEASUREMENTS OF PRODUCED WATER . . . . 19

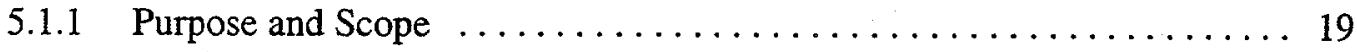

5.1 .2 Progress ....................................... 19

6. BIOCHEMICAL ENGINEERING $\ldots \ldots \ldots \ldots \ldots \ldots \ldots \ldots \ldots \ldots \ldots \ldots \ldots$

6.1 GREEN BIOPOL YMERS FOR IMPROVED DECONTAMINATION

OF METALS FROM SURFACES: SORPTIVE CHARACTERIZATION

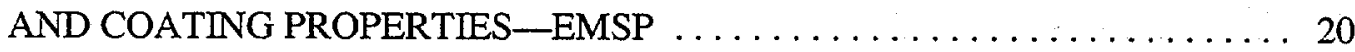

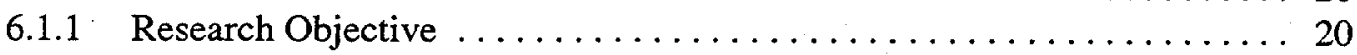

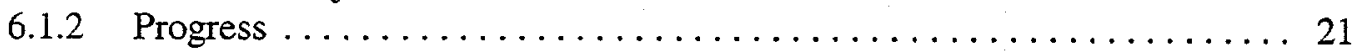

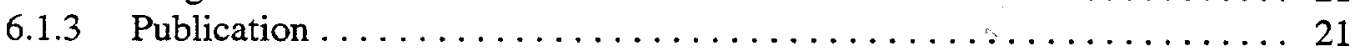

6.2 FUNDAMENTAL ENGINEERING FOR BIOFILTRATION-EMSP . . . . . 21 
6.2.1 Project Description $\ldots \ldots \ldots \ldots \ldots \ldots \ldots \ldots \ldots \ldots \ldots \ldots \ldots \ldots \ldots \ldots \ldots \ldots \ldots, 22$

$6.2 .2 \quad$ Progress $\ldots \ldots \ldots \ldots \ldots \ldots \ldots \ldots \ldots \ldots \ldots \ldots \ldots \ldots \ldots \ldots \ldots \ldots \ldots, 22$

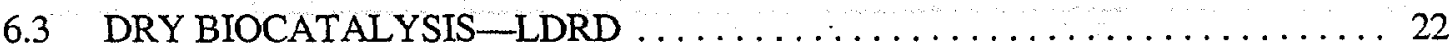

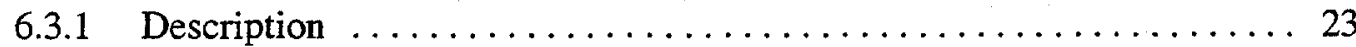

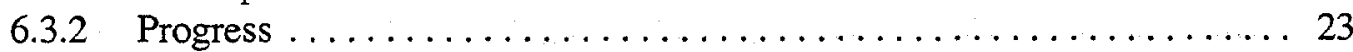

6.4 ENZYMATIC UPGRADING OF HEAVY CRUDES VIA PARTIAL

OXIDATION OR CONVERSION OF PAHs $\ldots \ldots \ldots \ldots \ldots \ldots \ldots \ldots \ldots .24$

6.5 BIOLOGICAL DESULFURIZATION OF DIESEL AND PETROLEUM

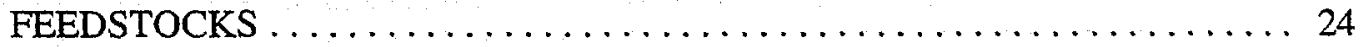

6.6 CHARACTERIZATION OF CHEMICALLY MODIFIED ENZYMES

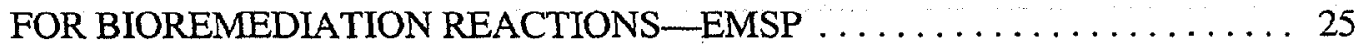

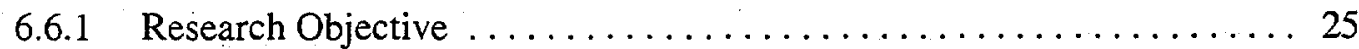

6.6.2 Research Progress and Implications .................. 25

6.6.2.1 PEG Modification of LiP and Its Bioremediation Applications .. 26

6.6.2.2 Fundamentals of Modified Enzymes in Organic Solvents . . . . 26

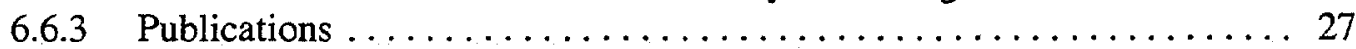

6.7 SUCCINIC ACID PRODUCTION FROM LIGNOCELLULOSIC

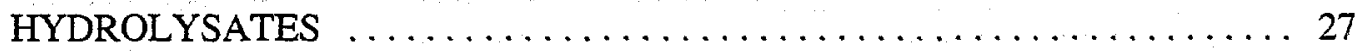

6.8 ADVANCED REACTOR DESIGN FOR FUEL ETHANOL PRODUCTION $\ldots 28$

7. SEPARATIONS AND MATERIALS SYNTHESIS $\ldots \ldots \ldots \ldots \ldots \ldots \ldots \ldots \ldots \ldots$

7.1 CHEMICAL AND PHYSICAL PRINCIPLES IN MULTIPHASE

SEPARATIONS ..................................... 29

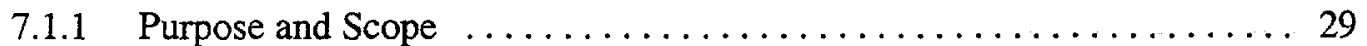

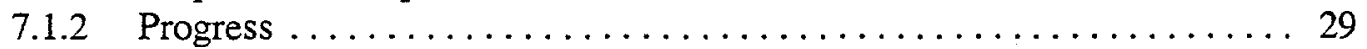

7.1.2.1 Electrohydrodynamic Spraying and Mixing ........... 29

7.1.2.2 Gas-Liquid Hydrodynamics in Macroporous Media . . . . . . . 29

7.1.2.3 Particle Interactions Under Magnetic Fields ........... 30

7.2 NUCLEATION, GROWTH, AND TRANSPORT PHENOMENA IN

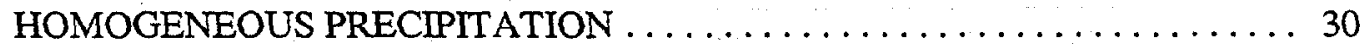

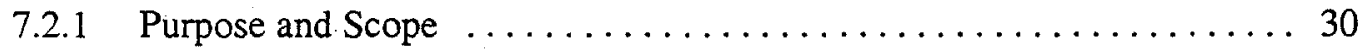

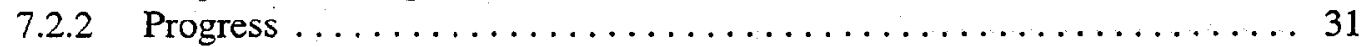

7.3 PHASE EQUILIBRIA MODIFICATION BY ELECTRIC FIELDS $\ldots \ldots \ldots \ldots 31$

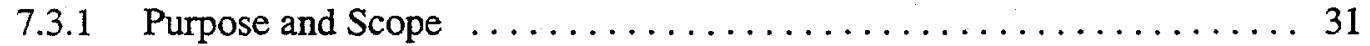

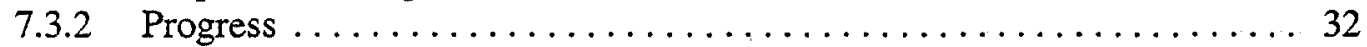

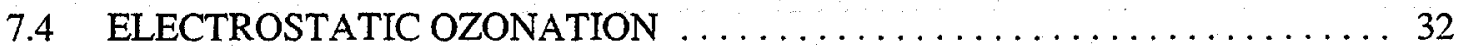

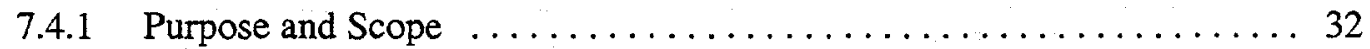

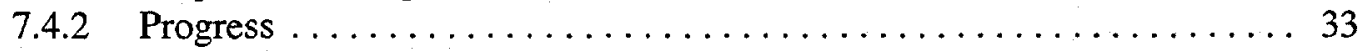


7.5 OZONE TREATMENT OF SOLUBLE ORGANICS IN PRODUCED

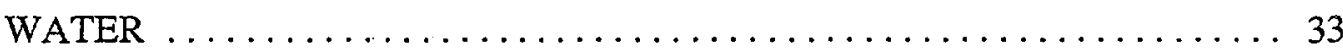

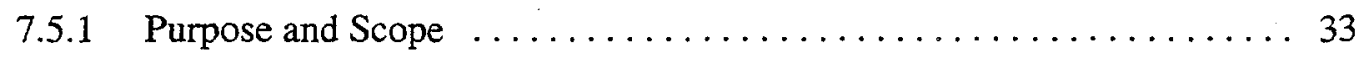

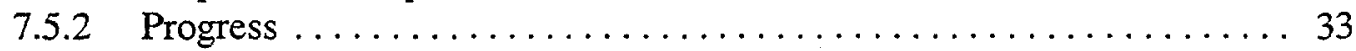

7.6 ELECTRICALLY DRIVEN TECHNOLOGIES FOR RADIOACTIVE

AEROSOL ABATEMENT $\ldots \ldots \ldots \ldots \ldots \ldots \ldots \ldots \ldots \ldots \ldots \ldots \ldots \ldots \ldots \ldots \ldots$

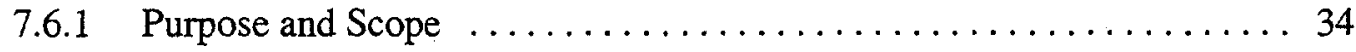

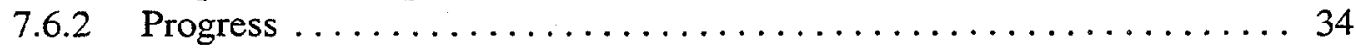

7.7 IMPROVED DECONTAMINATION: INTERFACIAL, TRANSPORT, AND CHEMICAL PROPERTIES OF AQUEOUS SURFACTANT CLEANERS $\ldots \ldots \quad 35$

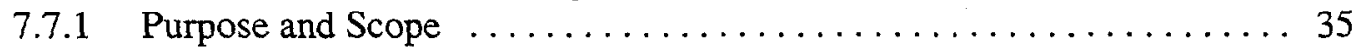

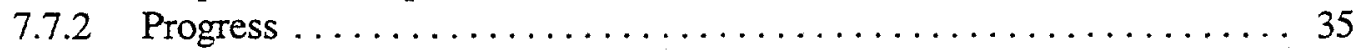

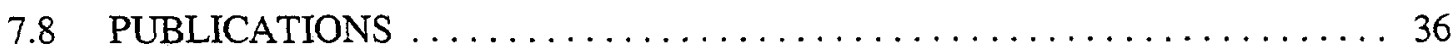

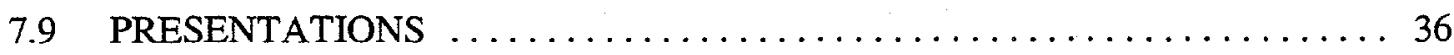

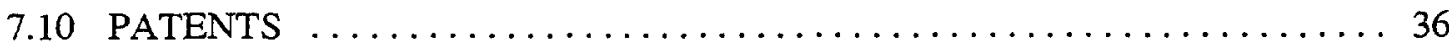

8. FLUD STRUCTURES AND PROPERTIES $\ldots \ldots \ldots \ldots \ldots \ldots \ldots \ldots \ldots \ldots \ldots \ldots \ldots$

8.1 INTERACTIONS OF SOLUTES, SOLVENTS, AND SURFACES . . . . . . . 37

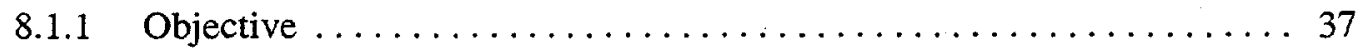

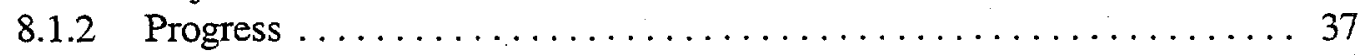

8.2 MOLECULAR-BASED STUDY OF REVERSE MICELLES IN

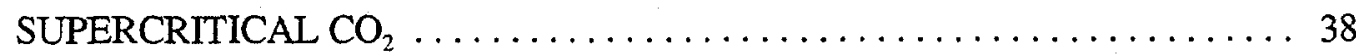

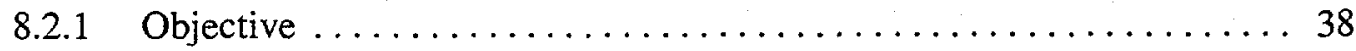

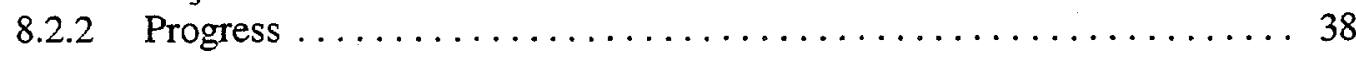

8.3 STRUCTURE AND PROPERTIES OF CHAIN MOLECULE SYSTEMS

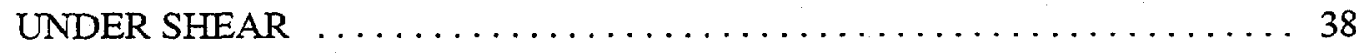

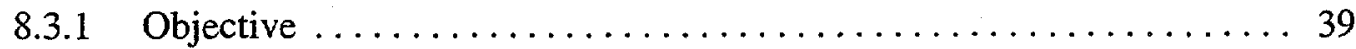

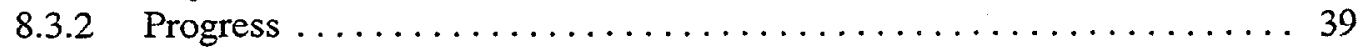

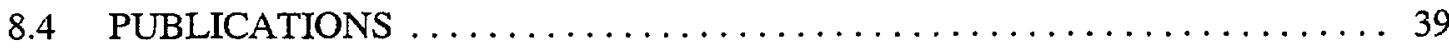

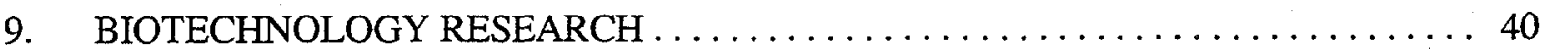

9.1 KINETICS OF ENZYME-CATALYZED REACTIONS $\ldots \ldots \ldots \ldots \ldots \ldots, 40$

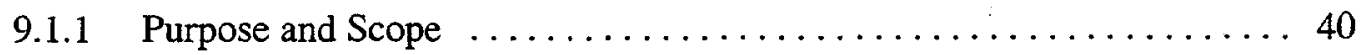

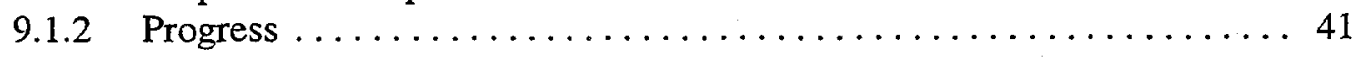

9.2 BIOMOLECULAR ELECTRONICS $\ldots \ldots \ldots \ldots \ldots \ldots \ldots \ldots \ldots \ldots, 41$

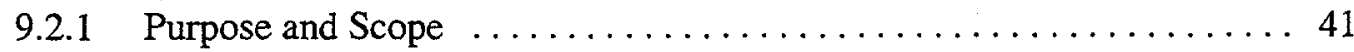

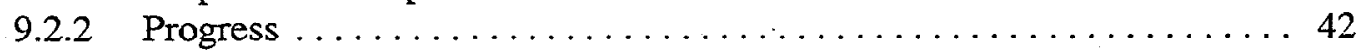

9.3 RENEWABLE HYDROGEN PRODUCTION BY PHOTOSYNTHETIC

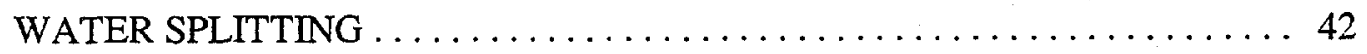




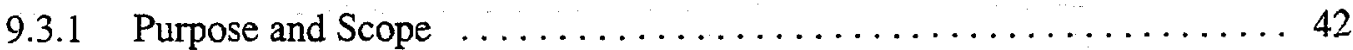

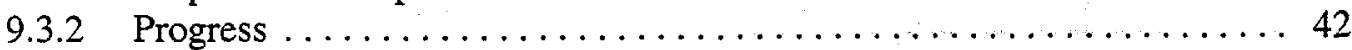

9.4 FLUOROMETRIC TISSUE-BASED BIOSENSORS $\ldots \ldots \ldots \ldots \ldots \ldots \ldots . \ldots 4$

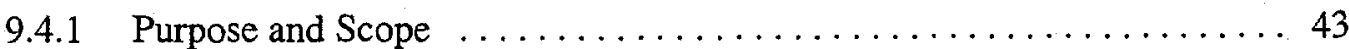

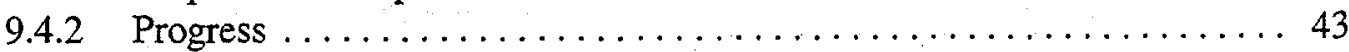

9.5 CELLULASES WITH ENHANCED ACTIVITY $\ldots \ldots \ldots \ldots \ldots \ldots \ldots \ldots \ldots \ldots \ldots$

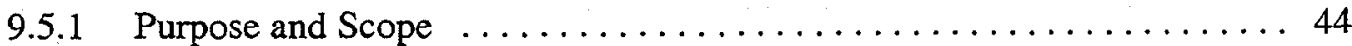

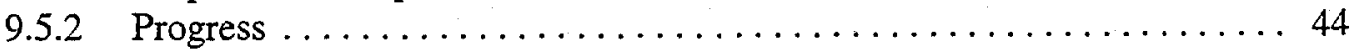

9.6 DEVELOPMENT OF A FUEL CELL ..................... 44

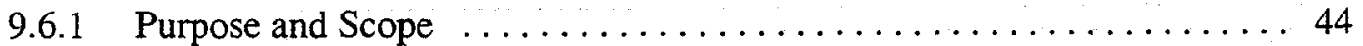

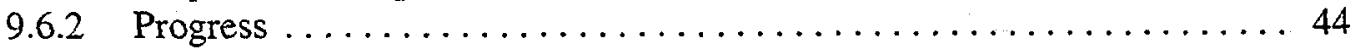

9.7 HYDROGEN PRODUCTION FROM RENEWABLES $\ldots \ldots \ldots \ldots \ldots \ldots \ldots \ldots$

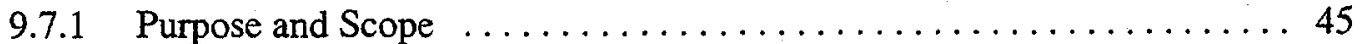

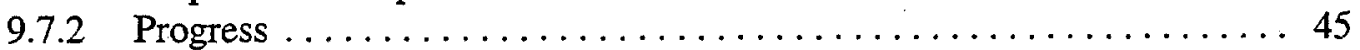

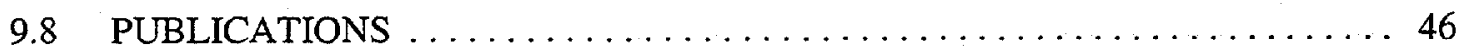

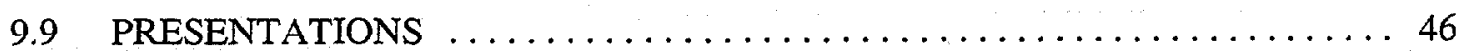

10. MOLECULAR STUDIES $\ldots \ldots \ldots \ldots \ldots \ldots \ldots \ldots \ldots \ldots \ldots \ldots \ldots \ldots \ldots$

10.1 AQUEOUS ELECTROLYTE SOLUTIONS AT AMBIENT AND

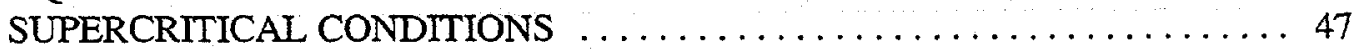

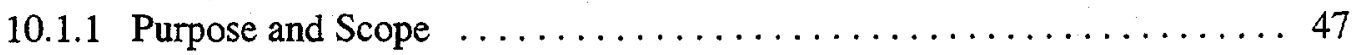

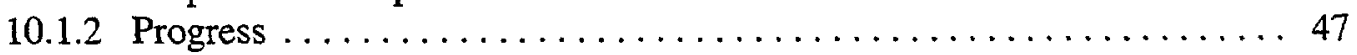

10.2 THEORY AND MOLECULAR SMMULATION OF NONEQUILIBRIUM

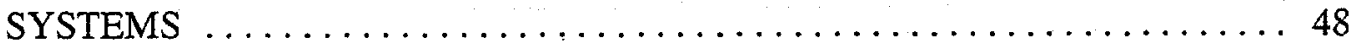

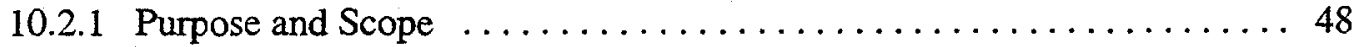

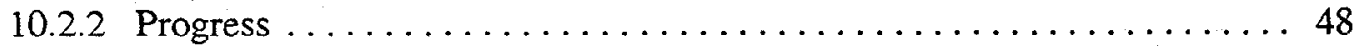

10.3 INTEGRAL EQUATION THEORIES OF MOLECULAR FLUIDS $\ldots \ldots \ldots \ldots 48$

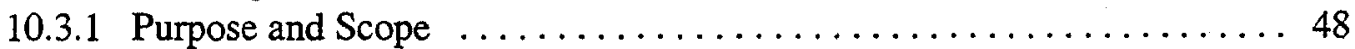

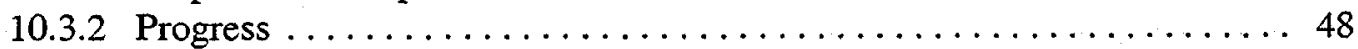

10.4 MATHEMATICAL MODELING OF BACTERIAL MIGRATION THROUGH POROUS MEDLA WITH APPLICATION TO IN SITU BIOREMEDIATION ... 49

10.4.1 Purpose and Scope $\ldots \ldots \ldots \ldots \ldots \ldots \ldots \ldots \ldots \ldots \ldots . \ldots \ldots$

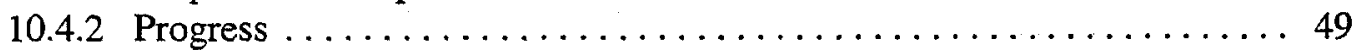

10.5 FUNDAMENTAL CHEMISTRY AND THERMODYNAMICS OF HYDROTHERMAL OXIDATION PROCESSES $\ldots \ldots \ldots \ldots \ldots \ldots \ldots \ldots . \ldots 49$

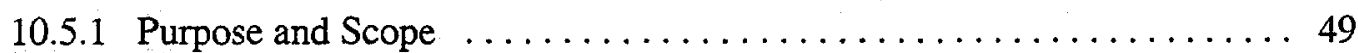

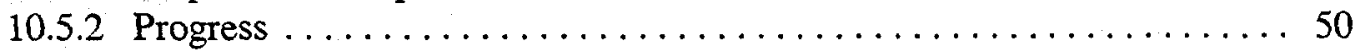

10.6 DEVELOPMENT AND APPLICATION OF FAST COMPUTATIONAL 
PROTEIN-FOLDING ALGORITHMS USING MASSIVELY PARALLEL

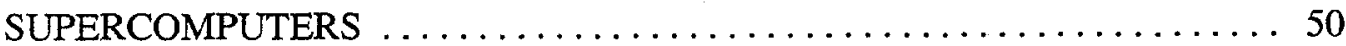

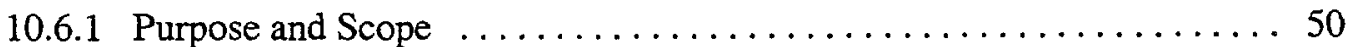

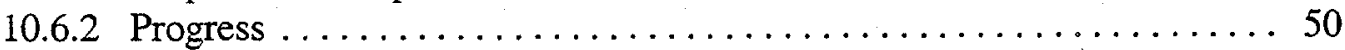

10.7 MOLECULAR-BASED STUDY OF REVERSE MICELLES IN

SUPERCRITICAL CARBON DIOXIDE FOR SOLVENT SUBSTITUTION

IN THE U.S. CHEMICAL INDUSTRY $\ldots \ldots \ldots \ldots \ldots \ldots \ldots \ldots \ldots \ldots \ldots . . \ldots$

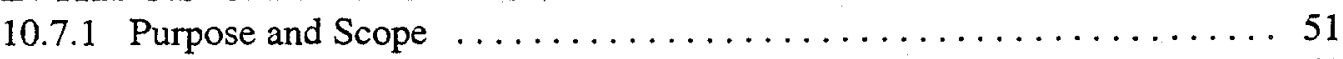

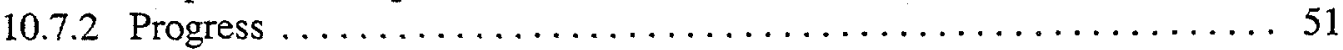

10.8 NANOTECHNOLOGY WITH EMPHASIS ON TRIBOLOGY: A COMBINED

EXPERIMENTAL AND SIMULATION STUDY $\ldots \ldots \ldots \ldots \ldots \ldots \ldots \ldots, 51$

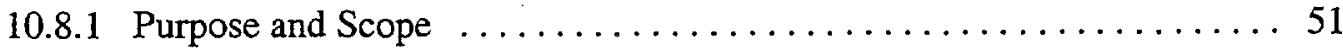

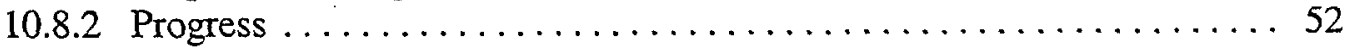

10.9 OTHER IMPORTANT ACTIVITIES $\ldots \ldots \ldots \ldots \ldots \ldots \ldots \ldots \ldots \ldots \ldots \ldots \ldots \ldots \ldots$

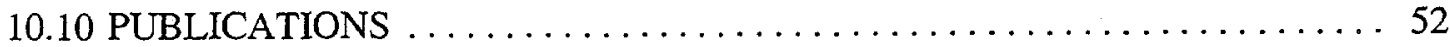

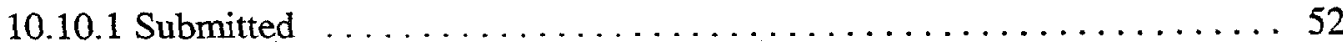

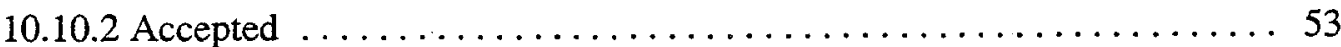

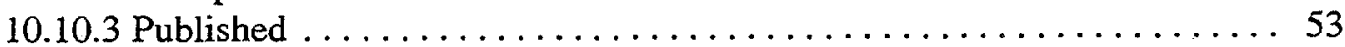

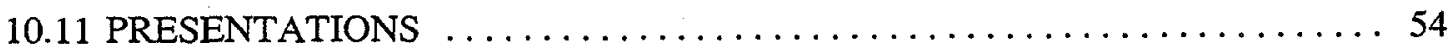

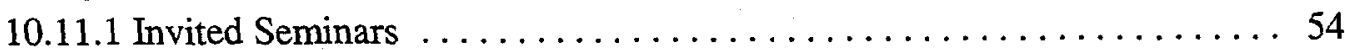

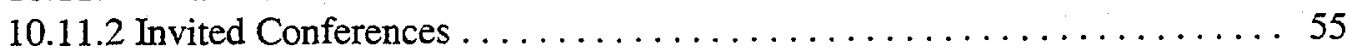

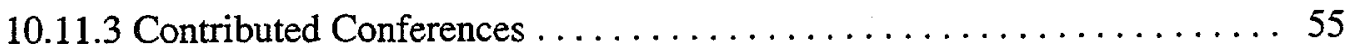




\title{
ACRONYMS AND ABBREVIATED FORMS
}

\author{
AOR \\ aldehyde ferredoxin reductase \\ BET \\ Brunauer-Emmett-Teller (isotherm) \\ BJH \\ BTEX \\ Bopp-Jancsó-Heinzinger (method) \\ BTMSen \\ CBD \\ benzene, toluene, ethylbenzene, xylene \\ CERS \\ bis[(3-trimethoxysilyl)propyl] ethylenediamine \\ cellulose-binding domain \\ CHAPS \\ CSIC \\ CSTR \\ CTAB \\ CWA \\ DBS \\ DF \\ DLS \\ DMSO \\ DOE \\ DU \\ EHD \\ EMSP \\ EPA \\ ESP \\ FBR \\ Fd \\ FTIR \\ Chemical and Energy Research Section \\ 3-[(3-cholamidopropyl)-dimethylammonio]-1-propanesulfonate \\ Consejo Superior de Investigaciones Cientificas (Madrid, Spain) \\ continuously stirred tank reactor \\ cetyltrimethylammonium bromide \\ chemical warfare agent \\ dibutylsulfide \\ decontamination factor \\ dynamic light scattering \\ dimethyl sulfoxide \\ U.S. Department of Energy \\ depleted uranium \\ electrohydrodynamic \\ Environmental Management Science Program (DOE) \\ U.S. Environmental Protection Agency \\ Environmental Simulation Program \\ fluidized-bed reactor \\ ferredoxin \\ Fourier transform infrared \\ HFIR \\ HLW \\ High Flux Isotope Reactor \\ high-level waste \\ HPLC \\ ICP \\ INEEL \\ LDRD \\ LiP \\ MALDI-TOF \\ $\mathrm{MeCN}$ \\ MPI \\ MSRE \\ MST \\ NaTPB \\ OBG \\ OHF \\ ORNL \\ PAH \\ PCP \\ PEG \\ PERF \\ PSI \\ high-performance liquid chromatography \\ inductively coupled plasma \\ Idaho National Engineering and Environmental Laboratory \\ Laboratory Director's Research and Development (funding) \\ lignin peroxidase (ligninase) \\ matrix-assisted laser desorption/ionization-time-of-flight (mass spectroscopy) \\ acetonitrile (methyl cyanide) \\ Multi-Point Injection TM \\ Molten Salt Reactor Experiment \\ monosodium titanate \\ sodium tetraphenylborate \\ Old Burial Ground (Hanford) \\ Old Hydrofracture [Tanks( ORNL)] \\ Oak Ridge National Laboratory \\ polyaromatic hydrocarbon \\ pentachlorophenol \\ polyethylene glycol \\ Petroleum Environmental Research Forum \\ Photosystem I \\ RCRA \\ Resource Conservation and Recovery Act
}


RPP

SALS

SANS

SAXS

SDS

SHF

SNF

SNS

SRS

SSF

TBA

TCE

TEOS

TFA

TMOS

TPB

TCBQ

$\mathrm{XRD}$
River Protection Project (Hanford)

small-angle light scattering

small-angle neutron scattering

small-angle $X$-ray scattering

sodium dodecyl sulfate

separate hydrolysis and fermentation

spent nuclear fuel

Spallation Neutron Source

Savannah River Site

simultaneous saccharification and fermentation

tributylamine

trichloroethylene

tetraethylorthosilicate

Tanks Focus Area

tetramethylorthosilicate

tetraphenylborate

tetrachlorobenzoquinone

$\mathrm{X}$-ray diffraction 


\section{EXECUTIVE SUMMARY}

This report summarizes the major activities conducted in the Chemical and Energy Research Section of the Chemical Technology Division at Oak Ridge National Laboratory (ORNL) during the period July-September 1999. The section conducts basic and applied research and development in chemical engineering, applied chemistry, and bioprocessing, with an emphasis on energy-driven technologies and advanced chemical separations for nuclear and waste applications.

The report describes the various tasks performed within ten major areas of research: Hot Cell Operations, Process Chemistry, Molten Salt Reactor Experiment (MSRE) Remediation Studies, Chemistry Research, Physical Properties Research, Biochemical Engineering, Separations and Materials Synthesis, Fluid Structures and Properties, Biotechnology Research, and Molecular Studies. The name of a technical contact is included with each task described, and readers are encouraged to contact these individuals if they need additional information.

Activities conducted within the area of Hot Cell Operations involved the testing of two continuously stirred tank reactors in series to evaluate the Savannah River-developed process of small-tank tetraphenylborate precipitation to remove cesium, strontium, and transuranics from supernatant.

Within the area of Process Chemistry, various topics related to solids formation in process solutions from caustic treatment of Hanford sludge were addressed. Saltcake dissolution efforts continued, including the development of a predictive algorithm. New initiatives for the section included modeling activities centered on detection of hydrogen in ${ }^{233} \mathrm{U}$ storage wells and wax formation in petroleum mixtures, as well as support for the Spallation Neutron Source (investigation of transmutation products formed during operation). Other activities involved in situ grouting and evaluation of options for use (i.e., as castable shapes) of depleted uranium.

In a continuation of activities of the preceding quarter, MSRE Remediation Studies focused on recovery of ${ }^{233} \mathrm{U}$ and its conversion to a stable oxide and radiolysis experiments to permit remediation of MSRE fuel salt. Investigation of options for final disposition of the ${ }^{233} \mathrm{U}$ inventory represents a new initiative within this area.

In the area of Chemistry Research, activities included studies relative to molecular imprinting for use in areas such as selective sorption, chemical sensing, and catalysis, as well as spectroscopic investigation into the fundamental interaction between ionic solvents and solutes in both low- and high-temperature ionic liquids.

Physical Properties Research efforts investigated the production of water-soluble organics, which pose a special treatment problem for the petroleum industry.

Within the area of Biochemical Engineering, efforts were directed toward metal decontamination using environmentally benign polymers, biofiltration and "dry" enzymes for the treatment of volatile organic compounds, enzyme-based upgrade of heavy oils, and biological desulfurization of partially oxidized diesel fuel. Other initiatives included the characterization of chemically modified enzymes for bioremediation reactions, the production of succinic acid from industrial lignocellulosic hydrolysates, and the development of advanced reactors for enhanced biofuel ethanol production.

In the area of Separations and Materials Synthesis, fundamental studies explored the use of electromagnetic fields to enhance transport processes in multiphase separations, investigated 
nucleation and particle growth for advanced material synthesis and processing, and examined the use of electric fields to modify phase equilibria in multiphase separations processes. Other efforts involved enhanced oxidation of organic pollutants in aqueous solutions by applying electric fields to form microbubbles, the use of ozonation to treat water-soluble organics, the application of electrical and acoustic methods to remediate aerosol problems, and the development of improved means of decontamination using aqueous surfactant cleaners.

Fluid Structures and Properties included molecular-based studies of systems with supercritical solvents; a multi-institutional initiative to develop a molecular understanding of reverse miscelles in supercritical carbon dioxide through experimentation as well as molecular simulation calculations; and quantitative, molecular-based prediction of the structure and properties of long-chain molecules undergoing shear flow.

Within the area of Biotechnology Research, tasks included research into fundamental reactions of photosynthesis, construction of molecular optoelectronic devices, investigation of renewable hydrogen production by photosynthetic water splitting, and utilization of microalgae as biosensors. In enzyme-related work, studies were undertaken to improve biocatalysts by increasing the catalytic rate of hydrolysis of cellulose and to increase the efficiency of enzymatic production of hydrogen from glucose. Research continued to focus as well on nonenzymatic production of hydrogen, specifically from an iron-powder catalyst.

In the final area-Molecular Studies-as part of an effort to enhance our microscopic-level understanding of aqueous electrolyte solutions, simulations of supercooled water were continued. The investigation of simulation algorithms for nonequilibrium systems continued, and the ChialvoCummings solvation formalism was applied to electrolyte solutions. Production runs were performed using the parallelized Geocore algorithm, and large-system runs were conducted of the simulation code for reverse miscelles. In addition, production runs of the viscosity of perfluorobutane were performed, and molecular dynamics simulations of alkanes confined to nanoscale gaps were continued. 


\title{
1. HOT CELL OPERATIONS
}

\author{
E. C. BEAHM
}

\subsection{TESTING TWO CSTRS IN SERIES FOR THE SAVANNAH RIVER SMALL-TANK TPB PRECIPITATION SIMULATION (D. D. Lee, J. L. Collins, and C. W. Chase)}

\author{
Contact: D. D. Lee \\ Telephone: (865) 576-2689 \\ Internet: leedd@ornl.gov
}

Summary: One of the proposed methods of removing the cesium, strontium, and transuranics from the radioactive waste storage tanks at Savannah River is the small-tank tetraphenylborate (TPB) precipitation process. A two-reactor-in-series (15-L working volume each) continuous-flow stirred-tank-reactor (CSTR) system was designed, constructed, and installed in a hot cell to test the Savannah River-developed process. The system also includes two cross-flow filtration systems to concentrate and wash the slurry produced in the process, which contains the bulk of the radioactivity from the supernatant processed through the system. Installation, operational readiness reviews, and system preparation and testing were completed. The first test using the filtration systems, two CSTRs, and the slurry concentration system was conducted over a 61 -h period with design removal of $\mathrm{Cs}, \mathrm{Sr}$, and $\mathrm{U}$ achieved.

\subsubsection{Purpose and Scope}

Oak Ridge National Laboratory (ORNL) was asked to demonstrate the continuous small-tank TPB process at the bench scale in Technical Task Request HLW-SDT-TTR-99-03.0. The process was designed to effectively remove soluble cesium from the storage tank supernatant salt solutions, providing a means of separating large volumes of solution for disposal in saltstone. The precipitated cesium would be contained in a small volume of solids for disposal in glass. Monosodium titanate (MST) was added to adsorb $\mathrm{Sr}$ and actinides ( $\mathrm{Pu}, \mathrm{Np}$, and $\mathrm{U}$ ). In 1995, batch processing of the supernatant in Tank $48 \mathrm{H}$ was started, using sodium tetraphenylborate (NaTPB) to precipitate cesium. Production of benzene from TPB occurred during processing and led to the cessation of operations. Subsequent testing suggested that the decomposition was likely catalyzed by copper and palladium in the tank supernatant and sludge. (Other elements may contribute.) Elevated temperature, radiolysis, and the oxidation/reduction potential of the vapor/liquid system in the tank also influenced the decomposition rate.

The Savannah River High-Level Waste (HLW) Salt Disposition Program was created from a need to find alternatives to the in-tank precipitation process. Subsequently, the ORNL project was initiated as a response to a request for support for the preconceptual design phase for one of the "Short List" alternatives. No previous demonstration existed for operation of the precipitation reaction with material from the Savannah River Site (SRS) tank farm in a continuous fashion. Savannah River requested that ORNL conduct tests to confirm that the two-reactor-in-series configuration of CSTRs could perform the desired separations using simulated salt waste containing ${ }^{137} \mathrm{Cs}$ and ${ }^{85} \mathrm{Sr}$ as radioactive tracers.

One of the requirements was that the flowsheet be designed for maximum operational flexibility. To do so, it was necessary to incorporate the capacities to add a third CSTR, to change 
the residence time in each CSTR, to change the amount of excess TPB added to the first CSTR in the recycle wash water feed, and to add TPB to the second CSTR if required. The design variables that were considered during the planning for the CSTRs were mixing speeds, mixing direction, agitator types, cooling coils, and chemical concentrations. It also had to be determined whether the cooling coils could serve as draft tubes.

Because of potential foaming problems, the CSTRs had to be designed for the feed and product streams to enter below the liquid surface in order to minimize aeration, which causes foam formation. At the time of the equipment design, it was uncertain if an antifoaming agent would be required to control foaming; however, provisions were made for its addition.

\subsubsection{Progress}

The second test (Test 2), which was started and completed on schedule, integrated the TPB slurry washing and wash water recycle into the first CSTR. It was completed after $230 \mathrm{~h}$ of continuous operation. All of the CSTR systems performed as designed, and desired cesium and uranium decontamination factors (DFs) were achieved in both CSTRs and in the concentration filtrate. No foam problems were encountered in the system operation during the treatment of about $300 \mathrm{~L}$ of radioactive simulated waste. Approximately $25 \mathrm{~L}$ of greater than 7 to $10 \mathrm{wt} \%$ concentrated, precipitated washed slurry was collected. Eight liters of unwashed concentrated slurry was also produced by the end of the experiment. More than $435 \mathrm{~L}$ of decontaminated filtrate was collected from the concentration filtering system.

The strontium DF was obtained in the feed tank when some of the catalyst components that contained hydrous metal oxides, known to bind strontium, were added. The slurry washing step was completed four times on four successive batches of concentrated slurry, and the wash water, containing resolubilized Na TPB, was fed back into the first CSTR. Test 2 used the enhanced catalyst component system with five times higher levels of palladium. No degradation of the cesium DF was detected, and no measurable increase in the amount of TPB breakdown products was observed in any of the samples from the various vessels.

\section{PROCESS CHEMISTRY}

\section{E. C. BEAHM}

\subsection{PREVENTION OF SOLIDS FORMATION (R. D. Hunt, E. C. Beahm, T. A. Dillow, and C. F. Weber)}

Contact: R. D. Hunt

Telephone: (865) 574-5481

Internet: huntrd@ornl.gov

Summary: Aluminate/alumina, fluoride, hydroxide, nitrate, phosphate, silicon, and sulfate can potentially impact the viscosity of Hanford tank wastes. Samples that contained moderate or low concentrations of each component were prepared. Viscosity measurements were taken as the samples were gradually cooled from 80 to $10^{\circ} \mathrm{C}$ and as the samples were cooled from $50^{\circ} \mathrm{C}$ to ambient conditions in a simulated pump failure. Two samples formed high-viscosity gels during the gradual waste cooling, while a third sample formed a high-viscosity gel during the simulated pump 
failure. An analysis of the results indicated that phosphate concentration, ionic strength, and temperature are the key variables in the formation of plugged pipelines.

The transfer of waste from Hanford tank SX-104 led to a plugged transfer line. Based on the chemical analysis of the plug, the first chemical simulant of the SX-104 plug was prepared. Modifications to the initial formulations were also tested. At the conclusion of this evaluation, the best chemical process to simulate the SX-104 plug will be used in a university contest that will evaluate methods for removing plugs.

Silicate reactions with metals have been shown to interfere with waste processing operations. For example, the gravity drain line of the $242-16 \mathrm{H}$ evaporator at Savannah River became plugged with cancrinite, which is a nitrated sodium aluminosilicate. Therefore, it is important to understand silicate chemistry and to incorporate it into predictive tools. In response to this need, a model on the solubility of silicate species in caustic at $25^{\circ} \mathrm{C}$ was developed.

\subsubsection{Purpose and Scope}

Nuclear waste remediation efforts at Hanford and Savannah River have been adversely affected by unwanted or unintentional solids formation. Transfer pipes at Hanford and Savannah River have become plugged with the nuclear waste. These plugs have led to schedule delays and to higher remediation costs. Fortunately, operating windows where solids can form during tank operations such as pretreatment, transfers, and storage can be predicted. These windows are based on thermodynamic calculations that use ionic strengths and the concentrations of phosphate, fluoride, silica, alumina, and hydroxide. To improve process control, it will also be necessary to correlate chemical effects and solid formation with physical properties, which can be continuously monitored if necessary. The properties of interest in many operations are viscosity and specific gravity. The ultimate aim is to provide relationships between the chemistry and physical properties so that the tank farm operators can avoid unwanted or unintentional solids formation.

\subsubsection{Progress}

At the request of the Tanks Focus Area (TFA), a test plan for the FY 1999 research effort was submitted to the Pretreatment Technical Integration Manager. The approved test plan consists of the following research activities:

1. an evaluation of the formation of aluminosilicates during the caustic leaching of an actual sludge sample from a Hanford storage tank;

2. viscosity measurements of actual process waste solutions as a function of temperature;

3. tests with selected components to link their concentrations, temperatures, and viscosities (initial experimental design based on a two-level seven-factor partial factorial); and

4. tests in support of other TFA and user programs (primarily pipeline plugs).

\subsubsection{Viscosity Tests of Chemical Components in the Hanford Tank Waste (Task 3)}

Seven chemical components that could potentially impact the viscosities of Hanford tank wastes were identified. The components are aluminate/alumina, fluoride, hydroxide, nitrate, phosphate, silicon, and sulfate. While sodium and water are also present in each of the samples, they were not explicitly included as variables. A two-level seven-factor partial factorial was used to design the initial set of viscosity tests, which utilized only two concentrations for each component. 
Viscosity measurements were taken as the eight samples were gradually cooled from 80 to $10^{\circ} \mathrm{C}$ and as the samples were cooled from $50^{\circ} \mathrm{C}$ to ambient conditions in a simulated pump failure. Two samples formed high-viscosity gels during the gradual waste cooling, while a third sample formed a high-viscosity gel during the simulated pump failure. These three samples contained high concentrations of phosphate, while their ionic strengths were at least moderately high. In sharp contrast, the other sample with a high phosphate concentration and a low ionic strength did not form a high-viscosity gel. These results indicated that phosphate concentration and ionic strength are the key variables in the formation of plugged pipelines. A high silicon concentration in the presence of a high phosphate concentration may also play an important role in the formation of plugged pipelines. These current findings are supported by the results of investigations of line plugs at the Hanford tank farm. The most commonly identified compound in the Hanford plugs was sodium phosphate needles, which appeared during waste coolings. Future studies will determine the maximum concentrations of phosphate (and possibly silicon) and the maximum ionic strengths that are safe to transfer in the event of a pump failure.

These viscosity results can be used directly by the River Protection Project (RPP) at Hanford. Prior to a waste transfer by the RPP, the temperature of the waste must be at least $50^{\circ} \mathrm{C}$, and a maximum temperature loss during a transfer is expected to be $10^{\circ} \mathrm{C}$. Since the samples in our gradual waste cooling experiments did not form a high-viscosity gel until the temperature was below $35^{\circ} \mathrm{C}$, these viscosity results support the current transfer policy of the RPP. Our current and future viscosity results can be used to determine if a pump failure will likely lead to a plugged pipeline. In these cases, the RPP should make provisions to immediately switch to a second pump. The RPP can also use the viscosity results to determine the requirements for the water flushing after a waste transfer. Finally, this study demonstrated that the solids contents and viscosity of the waste prior to the transfer cannot be used to predict pipeline plugs. However, an accurate chemical analysis of a few key waste components can be helpful.

\subsubsection{University Contest on Methods to Unplug a Plugged Transfer Line (Task 4)}

The chemical analysis of the pipeline plug, which occurred during the transfer of waste from Hanford tank SX-104, was performed by Numatec Hanford personnel. These results were used to prepare the first chemical simulant of the SX-104 plug. The simulant contained sodium nitrate, sodium hydroxide, sodium phosphate, sodium carbonate, and sodium aluminate. The simulant was heated to $70-80^{\circ} \mathrm{C}$ before it was transferred to a small carbon steel pipe and permitted to cool to room temperature. The pipe then became plugged with solids. Modifications to the initial formulations were tested in small carbon steel pipes. An increase in the phosphate concentration assisted in the formation of simulated pipeline plugs. In contrast, the addition of the sodium silicate to the initial formulation seemed to reduce the potential for plugs. At the conclusion of this evaluation, the best chemical process to simulate the SX-104 plug will be used in a university contest that will evaluate methods for removing plugs.

\subsubsection{Operating Envelopes (Task 4)}

Silicates are present in many of the liquid wastes at Hanford and Savannah River. By themselves, silicates are quite soluble in highly alkaline solutions. However, in the presence of various metals, the solubility of the silicates decreases substantially due to the formation of complicated minerals such as kasolinite and cancrinite. These precipitation reactions decrease the solubility of metals such as aluminum, which would interfere with most waste strategies. In addition, cancrinite plugged the gravity drain line of the $242-16 \mathrm{H}$ evaporator at Savannah River. 
Therefore, it is important to understand silicate chemistry and to incorporate it into predictive tools, which describe tank contents and processing options. In response to this need, a model on the solubility of silicate species in caustic at $25^{\circ} \mathrm{C}$ was developed. During FY 2000, this model will be expanded to include aluminum and higher temperatures.

\subsubsection{Publications}

I. Matsubara, M. Paranthaman, A. Singhal, C. Vallet, D. F. Lee, P. M. Martin, R. D. Hunt, R. Feenstra, C.-Y. Yang, and S. E. Babcock, "Preparation of Textured YBCO Films Using All-Iodide Precursors," Physica C 319, 127-32 (1999). .

C. P. McGinnis, T. D. Welch, and R. D. Hunt, "Caustic Leaching of Nuclear High Level Waste Sludge: A Critical Literature Review," Sep. Sci. Technol. 34(6-7), 1479-94 (1999).

A. Singhal, G. Skandan, A. Wang, N. Glumac, B. H. Kear, and R. D. Hunt, "On Nanoparticle Aggregation During Vapor Phase Synthesis," Nanostruct. Mater. 11(4), 545-52 (1999).

G. N. Glavee, R. D. Hunt, and M. Paranthaman, "Low Temperature Preparation of $\mathrm{BaCeO}_{3}$ and $\mathrm{Ce}_{0.75} \mathrm{Zr}_{0.25} \mathrm{O}_{2}$ Thin Films Using Sol-Gel Processing Techniques," Mater. Res. Bull. 34(5), $817-25$ (1999).

G. Aeppli, S. M. Hayden, P. Dai, H. A. Mook, R. D. Hunt, T. G. Perring, and F. Dogan, "The Weights of Various Features in the Magnetic Spectra of Cuprates," Physica B 215(1), 519-22 (1999).

M. Z. Hu, R. D. Hunt, E. A. Payzant, and C. R. Hubbard, "Crystallization and Phase Transformation in Monodispersed Ultrafine Zirconia Particles from Various Homogeneous Precipitation Methods," J. Am. Ceram. Soc. 82(9), 2313-20 (1999).

\subsection{SALTCAKE DISSOLUTION (R. D. Hunt, M. R. Ally, E. C. Beahm, and C. F. Weber)}

Contact: R. D. Hunt

Telephone: (865) 574-5481

Internet: huntrd@ornl.gov

Summary: The high ionic strengths of the Hanford waste solutions can lead to uncertainties in equilibrium calculations. Therefore, a series of calculations using the Environmental Simulation Program (ESP) at Mississippi State University and the technique developed by Moonis Alley at ORNL was performed on concentrated sodium nitrate solutions. A comparison of the results indicates that uncertainties in the ESP calculations are not due to high ionic strengths. In addition, the chemical analysis of the Hanford wastes invariably leads to a significant difference in the number of cations and anions. ESP calculations were performed to determine the ion adjustments that were needed to balance the charge and to improve the fit between the calculated density and the measured density.

\subsubsection{Purpose and Scope}

This effort provides coordination and thermochemical evaluations in support of a team effort on Hanford saltcake dissolution. The tests on actual Hanford saltcake samples are conducted at 
Numatec Hanford, and the ESP simulations are performed by researchers at Mississippi State University. The primary objectives of this effort are to determine the solution conditions required to efficiently dissolve saltcake and to validate the ESP.

\subsubsection{Progress}

The high ionic strengths of the Hanford waste solutions can lead to uncertainties in equilibrium calculations. A series of comparison calculations with high-ionic-strength solutions was completed. Thermochemical properties of concentrated sodium nitrate solutions were calculated using the technique developed by Moonis Ally. These results were shown to be consistent with a fundamental requirement known as the Gibbs-Duhem equation. The results of ESP calculations on the same sodium nitrate solutions indicate that the uncertainties in the ESP predictions are not due to high ionic strengths.

A chemical analysis of saltcake samples invariably leads to a significant difference in the number of cations and anions. In any real system, the number of cations and anions must be the same. Calculations with the ESP were performed to determine the ion adjustments that were needed to balance the charge and to improve the fit between the calculated and the measured densities. These results were sent to Hanford as requested by the TFA.

\subsection{HANFORD SALTCAKE PREDICTIONS (M. R. Ally)}

Contact: M. R. Ally

Telephone: (865) 576-8003

Internet: allymr@ornl.gov

Summary: This task was designed to develop an algorithm for predicting the properties of concentrated sodium nitrate solutions to serve as a baseline case for comparing the performance of other software(s).

\subsubsection{Purpose and Scope}

The purpose of this report is to demonstrate the applicability of the ionic lattice model to describe and predict the properties of aqueous solutions from limited information.

\subsubsection{Progress}

The power of the ionic lattice model lies in the fact that only two pieces of information are necessary to determine thermodynamic properties of highly nonideal solutions over large variations in composition, concentration, and temperature. The results of the model are compared with experimental data where available. Predictions of the model to regions where there is an absence of data are also calculated and presented.

The water activities (and, consequently, water vapor pressures) for $\mathrm{NaNO}_{3}$ (aq) at 273.15, 373.15 , and $398.15 \mathrm{~K}$ are calculated. The rationale for using higher temperatures is that $\mathrm{NaNO}_{3}(\mathrm{aq})$ solubility increases with temperature, reaching a molality $(m)$ of approximately 27 at $398.15 \mathrm{~K}$. For 1:1 electrolytes, the molality and ionic strengths are identical (by definition). Predicted water vapor pressures and water activities are compared with experimental values (International Critical Tables). 
The mean ionic activity coefficient of the solute is predicted and compared with the isopiestic data of Stokes and Robinson (1959). The highest molality reported by Stokes and Robinson is 6 . The ionic lattice model is used to predict the values of the mean ionic activity coefficient to the saturation limit of $m=11.765$ at $273.15 \mathrm{~K}$.

The crystallization curve across the complete composition ranges from pure water (ice formation), where the ionic strength is zero, to pure anhydrous liquid $\mathrm{NaNO}_{3}(583.15 \mathrm{~K})$, where the ionic strength approaches infinity (described with this model). A predicted liquidus curve is compared with limited data from Linke and Sidell (1965). The accuracy in predicting the eutectic point $\left(-18.1^{\circ} \mathrm{C}\right)$ is noteworthy. According to the model, the eutectic occurs at an ionic strength of $\sim 5.8$.

\subsubsection{Publication}

M. R. Ally, "Liquidus Curves of $\mathrm{NaNO}_{3}$ (aq) Calculated from the Modified Adsorption Isotherm Model for Aqueous Electrolytes," Monatsh. Chem. (accepted).

\subsection{HYDROGEN DETECTION IN ${ }^{233}$ U STORAGE WELLS (M. R. Ally and K. J. Wills)}

Contact: M. R. Ally

Telephone: (865) 576-8003

Internet: allymr@ornl.gov

Summary: This effort verified the assumptions in a previously derived model to estimate the hydrogen content of the gaseous atmosphere that could possibly occur inside the tube vaults in Building 3019. The report that resulted suggested improvements and changes in the ${ }^{233} \mathrm{U}$ retrieval process to the Defense Nuclear Facilities Safety Board. The major assumptions in the model that were validated are as follows:

1. The shield plug does not form a seal with the tube-vault wall, thus allowing the hydrogen gas to diffuse past the shield plug to the upper section of the tube vault.

2. The tube-vault end cap leaks sufficiently to allow air to be drawn into the tube vault by the evacuation system, thereby purging hydrogen from the upper section of the vault.

3. Any hydrogen gas generated completely mixes with the other gases present in the lower section of the tube vault and does not stratify and concentrate beneath the shield plug.

4. Hydrogen, generated by the radiolytic decomposition of water, leaks from the cans under steadystate condition, as opposed to a sudden release resulting from rupture of the can(s)."

\subsubsection{Purpose and Scope}

The purpose of the ${ }^{233} \mathrm{U}$ Safe Storage Program is to enhance the safe storage of ${ }^{233} \mathrm{U}$-bearing materials. The published report, ORNL/TM-1999/188, describes the work done at ORNL's Radiochemical Development Facility to address questions related to possible hydrogen generation and

"This assumption was out of the scope of this investigation. 
accumulation in ${ }^{233} U$ tube vaults. The objective of this effort is to verify the assumptions in the model (stated in the summary for this section) to estimate the hydrogen content of the gaseous atmosphere that could possibly occur inside the tube vaults in Building 3019.

\subsubsection{Progress}

The efficacy of purging the upper section of the tube vault with nitrogen, instead of argon, as a safety measure under current Radiochemical Development Facility procedures, was analyzed. The rationale for using argon (the current procedure) was invalidated; an equivalent performance (and presumably greater cost savings) was achieved with nitrogen. Although displacing oxygen from above the shield plug by using nitrogen or argon purge gas was straightforward, the dilution of accumulated hydrogen below the shield plug requires special modifications in the shield plug design. An apparatus was designed, fabricated, and used to force argon or nitrogen (purge gases) through the center of the shield plug in an attempt to displace hydrogen below the plug in the lower section of the tube vault. Our tests determined that the latter is not a reliable option for hydrogen abatement because of variability in the construction of the shield plugs among tube vaults.

\subsubsection{Publication}

M. R. Ally and K. J. Wills, Analysis of Hydrogen Generation and Accumulation in U-233 Tube Vaults, ORNL/TM-1999/188, Oak Ridge National Laboratory, September 1999.

\subsection{WAX FORMATION IN PETROLEUM MIXTURES (M. R. Ally)}

Contact: M. R. Ally

Telephone: (865) 576-8003

Internet: allymr@ornl.gov

Summary: This effort developed an algorithm for predicting the solidus curve (wax formation) in alkane-alkane, alkane-aromatic, and aromatic-aromatic petroleum mixtures.

\subsubsection{Purpose and Scope}

Methods for predicting wax formation in petroleum mixtures require large amounts of experimental data and extensive correlation of the number of parameters. The purpose of this 1-month study was to determine if wax formation could be predicted with limited data and to validate the results over the entire composition range for an alkane-aromatic mixture.

\subsubsection{Progress}

Wax formation in an alkane-aromatic system was completed. The significant results are as follows: (1) the liquidus curve for wax formation (essentially, solid-phase precipitation) over the complete composition range (in terms of mole fraction) was computed, (2) the results were compared with experimental data, and (3) the maximum deviation between the computed and experimental data was $2.99 \%$ near the eutectic. 


\title{
2.5.3 New Projects
}

Moonis Ally has two new projects in collaboration with Thomas Thundat (Nanoscale Sciences and Devices Group). The first project, funded by the Federal Aviation Administration, is the National Safe Skies Alliance. The second project, with Ally as the principal investigator, is funded by the Office of Nonproliferation and Security (NN-20).

\subsubsection{Publication}

M. R. Ally, "Solute and Solvent Activities of $\mathrm{CaCl}_{2}$ (aq) Solutions from the Adsorption Isotherm Treatment," J. Chem. Eng. Data 44(4), 792-97 (1999).

\subsection{SPALLATION NEUTRON SOURCE SUPPORT (A. J. Mattus and C. F. Weber)}

\author{
Contact: A. J. Mattus \\ Telephone: (865) 576-1795 \\ Internet: mattusaj@ornl.gov
}

Summary: A program is under way to identify which accident scenarios are possible during operation of the Spallation Neutron Source (SNS) - using mercury as a target-and to determine what solutions are needed to handle or prevent them. The transmutation products formed during operation are being investigated through thermodynamic calculation and literature review to determine which products form stable hydrides over the operating temperature range of the SNS. In this way, we may establish whether there is a means for concentration of hydrogen in the system.

\subsubsection{Purpose and Scope}

During the operation of the SNS, a number of metallic and gaseous transmutation products are formed and have been identified and quantified using computer codes similar to ORIGEN. During 1 year, approximately $26 \mathrm{~L}$ of hydrogen at standard temperature and pressure will form in the $1 \mathrm{~m}^{3}$ of mercury utilized in the SNS target. The hydrogen gas formed will be a mixture of normal, deuterated, and tritiated isotopes. The question has been raised whether hydrogen can build up in concentration by reaction to form hydrides with numerous transmutation elements or react with mercury itself. Additionally, estimates of the volatilization rates of mercury during an accident in which a temperature excursion takes place have been requested in order to establish the practical, conservative limits of potential damage to human health and the environment. The results of this investigation will feed data into some aspects of the design of off-gas treatment systems and accident preparation procedures and equipment acquisition.

\subsubsection{Progress}

A draft report-to be issued as a Tech Note and later as an ORNL/TM report-has been completed this quarter. This report covers thermodynamically related issues of interest to the safe operation of the SNS that include the determination of which stable hydrides can form over an operational temperature range of 80 to $110^{\circ} \mathrm{C}$, as well as the potential for beam-stop temperature excursions. Results from calculation and literature searches reveal that only six hydrides can remain stable and, thereby, theoretically permit the buildup of normal hydrogen, deuterium, and tritium, mostly combined with noble metal by-products in the mercury. All other transmutation by-product elements were found to be incapable of forming hydrides under operating conditions. The few 
hydrides that can form are unstable in air and can either ignite or form pressure-sensitive compounds and explode. Even these hydrides may decompose since mercury acts as a catalyst to promote dispersion and decomposition to either metal, metal oxide, or amalgamated alloy. Additionally, it has been shown from the literature that by-product gases will not be soluble in the mercury. Additionally, volatilization rates of mercury following an accident scenario were also investigated and results presented to SNS safety staff. More data will be added to this report over the course of this fiscal year and the scope expanded as issues arise.

\title{
2.7 IN SITU GROUTING (R. D. Spence)
}

\author{
Contact: R. D. Spence \\ Telephone: (865) 574-6782 \\ Internet: spencerd@ornl.gov
}

Summary: A cold field demonstration at Odessa, Texas, finalized the grout formulation without a fluidizing admixture by using higher water contents in the jetting slurry grout. The grout formulation accommodated the higher water contents without compromising performance, widening the operating window. This demonstration proves the strategy of field adjustment to mix the thickest grout that can still be pumped-planned for the hot demonstration-as opposed to a fixed conservative fluid recipe with poorer monolith performance. The formulation used in the field at Odessa passed hot and cold laboratory testing of the Old Hydrofracture (OHF) Tanks sludge and cold testing of the $S 21$ tank sludge.

\subsubsection{Purpose and Scope}

The TFA is supporting tank closure by in situ grouting using Multi-Point Injection ${ }^{\mathrm{TM}}$ (MPI ${ }^{\mathrm{M}}$ ). The TFA proposes to demonstrate this technology by in situ grouting the tank heels in the OHF Tanks at ORNL and the Old Burial Ground (OBG) solvent tank S21 at SRS. An additional demonstration is scheduled for the tank heels remaining in tank TH-4 at ORNL after the bulk of the sludge has been excavated. The Chemical and Energy Research Section (CERS) supports this effort by developing the grout to (1) stabilize the tank sludge Resource Conservation and Recovery Act (RCRA) metals and radionuclides and (2) meet the processability requirements of the MPITM technique. MPI ${ }^{\mathrm{TM}}$ is an in situ jetting technique that can be used for in situ remediation of soil, shallow land burials, ponds/impoundments, and tanks. The grout formulation tailored for the needs of MPI ${ }^{\mathrm{TM}}$ was developed in FY 1996 in collaboration with Ground Environmental Services, the inventor and patent holder for MPITM. A cold field demonstration was successfully conducted in FY 1997 in Duncan, Oklahoma, simulating in situ grouting of TH-4 (a vertical cylindrical tank) before sludge excavation. CERS continues to support this effort by conducting laboratory hot and cold grout performance testing for specific tank wastes and by field consulting on grout performance.

\subsubsection{Progress}

A cold demonstration was successfully conducted during this reporting period at Odessa, Texas, on two horizontal cylindrical tanks-one simulating OHF Tanks and the other simulating OBG solvent tank S21. The grout formulation was revised and finalized for in situ grouting without the fluidizing admixture used in the Duncan cold demonstration. The fluidizing admixture allows thicker grouts to be pumped at high pressure and jetted into the tanks, significantly reducing the amount of water jetted into the tanks with the stabilizing additives. However, such organic admixtures are prohibited for many applications because of the potential mobilizing effect of the 
organic products resulting from radiolysis of the organic. The revised formulation without the fluidizer includes more water and was tested in the laboratory with cold simulants of both the OHF heel and the OBG S21 heel and with an actual hot OHF sludge sample. The revised grout formulation still did not develop any visible free water (despite the additional water required), set into a firm solid overnight, developed compressive strengths over $1000 \mathrm{psi}$, and passed the Toxicity Characteristic Leach Procedure Universal Treatment Standards limits. The revised grout meets the criteria for in situ grouting of all three tanks-OHF, OBG S21, and TH-4. A hot field demonstration is currently scheduled for the OHF during FY 2000.

\subsection{USEFUL CASTABLE DU SHAPES FOR THE DEPLETEDURANIUM ROADMAP (R. D. Spence)}

Contact: R. D. Spence

Telephone: (865) 574-6782

Internet: spencerd@ornl.gov

Summary: A roadmap was prepared for the use and disposition of the depleted uranium (DU) that will result after the conversion of all the depleted uranium hexafluoride (DUF $)$ currently stored at the gaseous diffusion plants.

\subsubsection{Purpose and Scope}

The Department of Energy (DOE) is currently soliciting bids for the conversion of all the DU currently stored around the country into a safe, stable form. This uranium, mainly $\mathrm{DUF}_{6}$, represents about 500,000 metric tons of equivalent DU. ORNL has a leading role in evaluating final use/disposition options for this DU after conversion and providing a DU roadmap to assist the DOE Office of Nuclear Energy Science and Technology in planning for the uses and disposition of the converted DU. The Chemical Technology Division has the lead role within ORNL, and CERS is supporting this effort by assisting in the evaluation of useful castable DU shapes such as DUCRETE ${ }^{T M}$ shielding casks and in a general review of the DU roadmap.

\subsubsection{Progress}

The candidates identified for this option were DUCRETETM, PYRUCTM, DUPoly, and other shielding composites. The main beneficial use identified for these materials was to provide a combination of gamma and neutron shielding. Ostensibly such materials are cheaper and/or thinner (hence lighter) than the currently used alternatives. The high-temperature manufacturing costs required to protect against the destructive oxidation of the $\mathrm{UO}_{2}$, its high density making it the most attractive oxide for the proposed use, appear to make this alternative more costly than simple disposition of the converted DU at the Nevada Test Site. Proponents argue that DOE can benefit from financing such spent nuclear fuel (SNF) shielding casks by avoiding (1) DU disposal costs (which would be passed along to the shield purchaser) and (2) the potential legal obligation for DOE to pay the costs of SNF storage now bome by the utilities. DOE can resolve two issues simultaneously - the DU problem and the SNF storage problem.

CERS assisted in writing a white paper on this option that was incorporated into the DU roadmap, participated in the DU Roadmap Workshop in August 1999, and reviewed the written version of the DU roadmap prepared by the Chemical Technology Division. 


\title{
3. MSRE REMEDIATION STUDIES
}

\author{
D. F. Williams
}

\subsection{URANIUM CONVERSION (G. D. Del Cul, A. S. Icenhour, D. W. Simmons, and J. Caja)}

Contact: G. D. (Bill) Del Cul

Telephone: (865) 241-3596

Internet: delculgd@ornl.gov

Summary: Fissile ${ }^{233} \mathrm{U}$ is presently being recovered, trapped, and removed as an essential part of the remediation and decommissioning activities presently under way at the Molten Salt Reactor Experiment (MSRE). Uranium hexafluoride trapped in NaF, along with uranium-laden activated charcoal, represents the bulk of the inventory. For permanent storage, all of the uranium needs to be recovered and transformed into a stable oxide. Efforts focused on prototypical conversion of the $\mathrm{UF}_{6}$ sorbed on $\mathrm{NaF}$, preparation of uranium-laden passivated charcoal (auxiliary

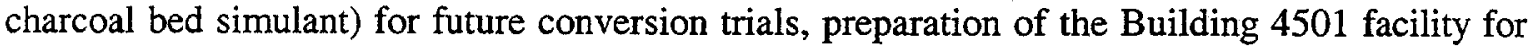
conversion operations, and assembly and identification of the cold-test (mock-up) apparatus. The conversion facility is scheduled to start the actual conversion operation in August 2000.

\subsubsection{Purpose and Scope}

The MSRE at Oak Ridge has been shut down since 1969, when the fuel salt was drained from the core into two drain tanks at the reactor site. In January 1994, analytical measurements of gas samples taken from the gas piping circuitry connected to the drain tanks indicated the presence of fluorine, $350 \mathrm{~mm} \mathrm{Hg}$, and uranium hexafluoride, $70 \mathrm{~mm} \mathrm{Hg}$. Although radiolysis was known to generate $\mathrm{F}_{2}$, the formation of $\mathrm{UF}_{6}$ and its transport from the fuel salt were unexpected. Additional investigation confirmed the belief that these gaseous products had moved through the piping to a charcoal bed. After these findings, a multiyear project was launched to remediate the potentially hazardous conditions generated by the movement of fissile material and reactive gases.

The extensive remediation and clean-up activities related to the MSRE involve (1) the trapping of the gaseous products; (2) deactivation, removal, and recovery of the uranium-laden activated charcoal; (3) stabilization and reconditioning of the fuel salt; and (4) conversion of ${ }^{233} \mathrm{U}$ compounds into a stable oxide for final safe storage and disposition. One of the essential tasks is the recovery and conversion of all of the ${ }^{233} \mathrm{U}$ materials into a stable oxide for permanent storage.

\subsubsection{Progress}

Much of the activity during this period was a continuation of tasks begun earlier. The design of the conversion process is nearly complete and is progressing toward as-built, $100 \%$ completion. Major components are being fabricated. Off-the-shelf procurement of instrumentation, piping, valves, and fittings is under way. The final process is being installed in the Building 4501 high bay, and it will be cold tested prior to installation in hot cell D. A mock-up of the hot cell walls has been installed in the high bay along with the in-cell table frame and crane. The manipulator mock-up located in the Building 4501 high bay is being used to test special tools required for use in the hot cell, and it will also be used to cold test the entire system. The air lock entrance to the facility was completed, and a buffer area covering the entrances to cells D and A is under construction. 
Prototype testing of $\mathrm{NaF}$ system was completed $(\sim 3 \mathrm{~kg}$ processed). Testing of the full-scale prototype for the recovery of uranium-laden charcoal is under way. The Safety Analysis Report and Technical Safety Requirements document for Building 4501 were submitted to DOE for review and approval. Plans and procedures (e.g., training, work control, operations, transportation) are being developed.

3.2 RADIOLYSIS AND MATERIALS DISPOSITION STUDIES (D. F. Williams, A. S. Icenhour, L. D. Trowbridge, L. M. Toth, J. Brynestad, and B. B. Spencer)

Contact: D. F. Williams

Telephone: (865)574-5769

Internet: williamsdf2@ornl.gov

Summary: Radiolysis experiments were conducted on $\mathrm{UO}_{2} \mathrm{~F}_{2}$ and uranium oxides using the ORNL ${ }^{60} \mathrm{Co}$ source and the High Flux Isotope Reactor (HFIR) SNF elements. Gas analyses showed that oxygen was released from the $\mathrm{UO}_{2} \mathrm{~F}_{2}$ matrix as a result of gamma irradiation. A damage limit to the $\mathrm{UO}_{2} \mathrm{~F}_{2}$ was demonstrated by the high-dose-rate exposure in the HFIR SNF. Successful trials were conducted that demonstrated that a progressive melting of the coolant salt from a central heating probe could be controlled and easily monitored. A separate smaller-scale experiment with an irradiated MSRE fuel salt simulant showed that fluorine is safely restored to the salt by hydrofluorination and that this treatment restores the salt to a homogenous melt without significant plating of active metals, corrosion, or formation of a solid heel.

\subsubsection{Purpose and Scope}

Understanding the radiolysis of MSRE fuel salt, uranium oxides, and other materials that derive from conversion of the recovered $\mathrm{UF}_{6}$ is necessary in order to proceed with remediation, interim storage, and permitted storage of the radioactive MSRE materials. The most significant remediation activities for the MSRE include (1) removal and recovery of uranium from the off-gas system, (2) removal of the uranium-laden charcoal from the charcoal bed, and (3) removal of the stored fuel salt. All of these retrievable intermediate materials are unsuitable for long-term storage and must be converted to a more stable form. In the case of the MSRE fuel salt, it is also necessary to understand the chemical consequences of the radiolysis in order to safely melt and treat the salt. A recent addition to the scope of this work has included short-term tests and analyses to support the interim storage of materials before they are converted into stable oxides.

\subsubsection{Progress}

Radiolysis studies were conducted in support of the development of the ${ }^{233} \mathrm{U}$ storage standard using the $\mathrm{ORNL}{ }^{60} \mathrm{Co}$ irradiator. A sample of $\mathrm{UO}_{2} \mathrm{~F}_{2}$ that had been burned in $\mathrm{O}_{2}$ to remove carbon was irradiated. Analysis of the gases produced by this sample showed that primarily $\mathrm{O}_{2}$ was produced, along with some $\mathrm{CO}_{2}$. This experiment proved that the oxygen released from radiolysis of the $\mathrm{UO}_{2} \mathrm{~F}_{2}$ was either in the form of $\mathrm{O}_{2}$ or $\mathrm{CO}_{2}$ (because of reactions with carbon impurities within the sample). A sample of converted uranium oxide from the conversion prototype was also irradiated. No pressure increase was observed for this sample. Finally, uranium oxide samples (i.e., $\mathrm{UO}_{3} \cdot x \mathrm{H}_{2} \mathrm{O}$ and $\mathrm{U}_{3} \mathrm{O}_{8}$ with sorbed water) were placed in the ${ }^{60} \mathrm{Co}$ irradiator. Similar to results of earlier experiments, an overall decrease in pressure during the irradiation was observed. 
The radiolysis experiment (started last quarter) that used HFIR SNF elements as the gamma source was completed. A sample of $\mathrm{UO}_{2} \mathrm{~F}_{2}$ was irradiated at high dose rates, and the pressure in the sample container was monitored throughout. The pressure was observed to rise and eventually reach a plateau, indicating that a damage limit had been reached. The total pressure rise was less than $1 \mathrm{~atm}$. Carbon dioxide was the primary gas produced.

The melting of $350 \mathrm{~kg}$ of MSRE coolant salt in a 24-in.-ID tank was conducted with a central $2.6-\mathrm{kW}$ melting probe assisted by blanket heaters to balance tank-wall heat losses. The progression of melting from the central probe was followed by wall and interior thermocouple measurements (located in prototypical fuel drain tank thimbles) and by actual measurement of the interface with an inserted measurement-probe. The change in slope of the temperature profile near $460^{\circ} \mathrm{C}$ was found to be a good indicator of local melting and agreed well with the.indications obtained by the inserted probe. The amount of tritium driven from the salt during these operations was small $(<0.3 \mathrm{mCi})$, and the final level of tritium in this tank of coolant salt was also low $(\sim 0.3 \mathrm{mCi}$ total, or $1 \mathrm{nCi} / \mathrm{g}$ ). A separate radiochemical analysis confirmed that no detectable activity exists in the coolant salt except for the trace level of tritium.

A small-scale test with radiolyzed MSRE fuel salt simulant $(800 \mathrm{~g}, 0.24 \mathrm{meq} / \mathrm{g}$ deficient in fluoride) was conducted to show that hydrofluorination was safe and effective for restoration of fluorine to the fuel salt. A $100-\mathrm{sccm}$ stream of $\mathrm{Ar}-4 \% \mathrm{H}_{2}$ was mixed with $4 \mathrm{sccm}$ of HF to treat the partially molten radiolyzed salt maintained at $600^{\circ} \mathrm{C}$. Progress of the hydrofluorination treatment was followed by measuring the consumption of HF. This HF consumption was measured by both Fourier transform infrared (FTIR) spectroscopy and by titration. Both methods gave consistent results. For most of the operation, the consumption of HFF was $75 \%$ of the maximum value. The entire period of adjustment lasted about $36 \mathrm{~h}$ - half at $75 \% \mathrm{HF}$ consumption and half at a decreasing consumption of $\mathrm{HF}$ (until a clear asymptotic HF breakthrough was established). After this treatment, the salt was completely molten, no heel was evident, and a homogeneous green salt phase was observed. Only minor levels of corrosion metals were measured in the treated salt $(<500 \mathrm{ppm})$.

These two studies (progressive melting from a central probe and hydrofluorination) support the use of a simultaneous progressive melting and chemical adjustment to restore fluorine to the radiolyzed fuel salt and thus ensure its complete melting and freedom from unwanted reaction or deposition. These two studies were documented in internal memos to MSRE project personnel that fulfilled project milestone obligations.

3.3 DISPOSITION OF ${ }^{233}$ U MATERIALS (G. D. Del Cul, W. H. Hermes, P. T. Singley, R. D. Spence, B. B. Spencer, L. D. Trowbridge, K. L. Walker, and C. C. Wynn)

Contact: G. D. (Bill) Del Cul

Telephone: (865)241-3596

Internet: delculgd@ornl.gov

Surmmary: DOE, in support of the U.S. arms-control and nonproliferation policies, has initiated a program for the disposition of surplus weapons-usable fissile materials. The goal is to make these materials inaccessible and unattractive for use in nuclear weapons. Different processes are being analyzed to select the best alternatives to convert the excess ${ }^{233} \mathrm{U}$ inventory to a form suitable for final disposition at a geological repository and in a form that is not useful for nuclear weapons. 


\subsubsection{Purpose and Scope}

The purpose of the program is to identify excess ${ }^{233} \mathrm{U}$ materials and to analyze the different processes in order to select the best option for converting the excess ${ }^{233} \mathrm{U}$ inventory to a form suitable for the final disposition at a geological repository and unusable for nuclear weapons. Because of the radiation field that accompanies these materials, the processing will be done inside hot cells. Special consideration will be given to the suitability of the different alternatives for hot cell operations; thus, reliable remote operations that require limited floor space are preferred. Another important consideration is the need to maintain a very low level of contamination on the packages to be transported. Many processes that are easy to operate in a conventional hands-on mode become very difficult or nearly impossible to conduct inside a hot cell.

The main goals for all of the alternatives are to minimize open, dusty operations; avoid difficult transfers between vessels; and prevent the escape of radon gas. Since there is some uncertainty about the amount of fissile materials and the actual concentration of neutron poisons in the materials to be processed, it is important to adhere to a critically safe geometry for all components of the process until criticality safety can be verified by other means (e.g., inventory limits or poison addition). Because of the need for hot cell containment, the selected process should involve very simple operations that minimize waste generation (especially liquid wastes). Because of the fissile nature of the material, a tight control of the fissile inventory must be an integral part of the design.

\subsubsection{Progress}

A matrix of options has been developed. The different alternatives are being screened at the conceptual level. Final disposition paths are being considered that target Yucca Mountain and the Waste Isolation Pilot Plant as the primary long-term storage sites. These options are being analyzed with consideration of the benefits and needs for integration of activities over the entire DOE complex. Most treatment alternatives include treatment stages at different DOE sites [e.g., ORNL, Savannah River, Idaho National Engineering and Environmental Laboratory (INEEL), and Hanford]. The main goal is to minimize the total disposition cost. Different hot cell facilities at ORNL are presently being evaluated.

\subsection{PRESENTATIONS}

D. F. Williams, A. S. Icenhour, L. D. Trowbridge, G. D. Del Cul, and L. M. Toth, "Radiolysis Studies in Support of the Remediation of the Molten Salt Reactor Experiment," invited presentation and paper to American Nuclear Society 1999 Winter Meeting, Long Beach, California, Nov. 14-18, 1999.

A. S. Icenhour, L. M. Toth, G. D. Del Cul, D. F. Williams, and L. D. Trowbridge, "Radiolysis Studies for the Long-Term Storage of ${ }^{233}$ Uranium Oxides," invited presentation and paper to American Nuclear Society 1999 Winter Meeting, Long Beach, California, Nov. 14-18, 1999. 


\title{
3.5 PUBLICATION
}

G. D. Del Cul, L. D. Trowbridge, L. M. Toth, and J. N. Fiedor, "Some Investigations of the Reaction of Activated Charcoal with Fluorine and Uranium Hexafluoride," J. Fluorine Chem., accepted for publication.

\section{CHEMISTRY RESEARCH}

\author{
D. F. Williams
}

\subsection{MOLECULAR IMPRINTING ON SOL-GEL MATRICES (S. Dai, Y. H. Ju, M. C. Burleigh, and S. D. Waezsada)}

Contact: S. Dai

Telephone: (865) 576-7307

Internet: dais@ornl.gov

Summary: A double-imprinting methodology has been used to synthesize mesoporous solgels containing a diaminoethane functionality. Formation of a bis[(3-trimethoxysilyl)propyl] ethylenediamine (BTMSen) metal complex, followed by hydrolysis and condensation with tetraethylorthosilicate (TEOS) in the presence of dodecylamine surfactant, results in the formation of the solid xerogel. Acid washing protonates the amino groups that release the metal ions. This results in the formation of binding sites that are uniquely designed with the coordination environment the given metal ion prefers. Mesopores are formed by the extraction of the surfactant micelles, giving this material relatively large surface areas and good mass transfer. A copper(II)imprinted gel has shown significant enhancement of copper(II) uptake capacities at various concentrations relative to a nonimprinted gel made without the metal-ion template. The imprinted material also exhibits improved selectivity for removal of copper(II) ions from $\mathrm{Cu}^{2+} / \mathrm{Zn}^{2+}$ aqueous solutions. A copper-imprinted sorbent that absorbed a total of $99.3 \%$ of the copper from a $10^{-4} \mathrm{M}$ aqueous solution achieved a $95 \%$ approach to equilibrium sorption within $15 \mathrm{~min}$. This material has copper distribution coefficients $\left(\mathrm{K}_{\mathrm{d}}\right)$ as high as 12,000 at $10^{-4} \mathrm{M}$. A separation factor [for copper(II)] greater than 85 was achieved with an aqueous $\mathrm{Cu}^{2+} / \mathrm{Zn}^{2+}$ system at $\mathrm{pH} 5.0$.

\subsubsection{Purpose and Scope}

The purpose of this research is to incorporate molecular recognition in advanced sorbent development. The design principles illustrated by these results highlight opportunities for application of imprint-coated mesoporous materials in areas such as selective sorption, chemical sensing, and catalysis.

\subsubsection{Progress}

The copper-imprinted sol-gel showed an enhanced capacity relative to the nonimprinted gel for the absorption of copper ions from aqueous solutions. A direct comparison shows the higher affinity of the imprinted gel for the $\mathrm{Cu}^{2+}$ ion and the resulting distribution coefficients. The imprinted sample absorbed more copper than the nonimprinted sample at all concentrations studied. Following the gel preparations, a nitrogen adsorption analysis was performed on each sample. The adsorption isotherms of the copper-imprinted and nonimprinted gels were very similar. The 
Brunauer-Emmett-Teller (BET) surface areas were 286 and $294 \mathrm{~m}^{2} / \mathrm{g}$ for the copper-imprinted and nonimprinted gels, respectively. The nearly identical surface areas indicate that the increased affinity of the copper-imprinted sample for the copper ion is not due to a larger available surface area. The maximum of the pore size distribution, calculated by the Bopp-Jancsó-Heinzinger (BJH) method, is slightly larger for the imprinted gel, but both show a rather broad distribution in the mesoporous range. Approximately $0.2 \mathrm{~g}$ of the copper-imprinted and nonimprinted gels were placed in separate vials with $20 \mathrm{~mL}$ of $10^{-3} \mathrm{MCu}^{2+}$ solution ( $\mathrm{pH} \mathrm{5.0)}$ and sonicated for $1 \mathrm{~h}$. The samples were then recovered by vacuum filtration and washed with deionized $\mathrm{H}_{2} \mathrm{O}$ and air dried. Diffuse reflectance spectra of these copper-imprinted and nonimprinted mesoporous powders loaded with adsorbed copper are compared with those of the aqueous spectra of $\left[\mathrm{Cu}(\mathrm{BTMSen})\left(\mathrm{H}_{2} \mathrm{O}\right)_{\mathrm{x}}\right]^{2+}$ and $\left[\mathrm{Cu}(\mathrm{BTMSen})_{2}\left(\mathrm{H}_{2} \mathrm{O}\right)_{x}\right]^{2+}$ complexes. The close match between the absorption bands of both mesoporous samples with those of $\left[\mathrm{Cu}(\mathrm{BTMSen})_{2}\left(\mathrm{H}_{2} \mathrm{O}\right)_{\mathrm{x}}\right]^{2+}$ indicates that each copper ion is adsorbed by two grafted BTMSen ligands. The absorption band of the nonimprinted sample is wider than that of the imprinted one, indicating a broader distribution of distinct copper complexes in the solid phase. The $\mathrm{pH}$ dependence for sorption of $\mathrm{Cu}^{2+}$ and $\mathrm{Zn}^{2+}$ was investigated over the $\mathrm{pH}$ range 3.0-5.5. The initial concentration of all solutions was $5 \times 10^{-3} \mathrm{M}$ in both copper and zinc. The sorption of both $\mathrm{Cu}^{2+}$ and $\mathrm{Zn}^{2+}$ was enhanced by increasing the $\mathrm{pH}$. Both the copper-imprinted and nonimprinted gels absorbed more $\mathrm{Cu}^{2+}$ than $\mathrm{Zn}^{2+}$ over the entire $\mathrm{pH}$ range. At $\mathrm{pH}$ values less than 5.0 , no zinc was absorbed.

\subsection{IONIC LIQUIDS RESEARCH (S. Dai and Y. H. Ju)}

Contact: S. Dai

Telephone: (865) 576-7307

Internet: dais@ornl.gov

Summary: Ionic liquids have been used as effective solvents to synthesize aerogels. A long aging time can be used to produce stable aerogel structures without supercritical drying processes.

\subsubsection{Purpose and Scope}

The purpose of this research is to conduct a spectroscopic investigation into the fundamental interaction between ionic solvents and solutes in both low-temperature and high-temperature ionic liquids (i.e., molten salts). The fundamental knowledge gained in these studies will be used to design novel separation systems involving ionic liquids.

\subsubsection{Progress}

Tetramethylorthosilicate (TMOS) is used as the sol-gel precursor. The room-temperature ionic liquid used in this work is 1-ethyl-3-methylimidazolium bis [(trifluoromethyl) sulfonyl] amide ( EtMelm $\left.{ }^{+} \mathrm{Tf}_{2} \mathrm{~N}^{-}\right)$. This melt is synthesized as described in the literature. Then the acid-catalyzed sol-gel processing is conducted. In a typical run, $1 \mathrm{~mL}$ of TMOS, $2 \mathrm{~mL}$ of formic acid (Aldrich Chemical Co., $99 \%$ ), and $1 \mathrm{~mL}$ of EtMelm ${ }^{+} \mathrm{Tf}_{2} \mathrm{~N}^{-}$were mixed. The final mixture gelled overnight and was cured at ambient temperature for 3 weeks. A transparent monolith glass was obtained. The entrapped ionic liquid was extracted by refluxing the above monolith in acetonitrile [Baker Chemical Co., high-performance liquid chromatography (HPLC) grade] overnight. The extraction procedure did not result in any visible shrinkage of the gel. This may be attributed to the long curing time used to stabilize the aerogel network before the extraction. The C-H stretching features (as measured by infrared spectroscopy) of the ionic liquid around $2900 \mathrm{~cm}^{-1}$ disappeared after extraction and vacuum 
drying. This indicates that all ionic liquid molecules were removed through extraction. Immersion of the aerogel in solvents with a high dielectric constant (e.g., water) can result in cracking of the aerogel monolith. However, the aerogel monolith is very stable in air. The $\mathrm{N}_{2}$ adsorption isotherm of the monolith glass after removal of the ionic liquid is identical to those of aerogels prepared using different solvents and supercritical extraction. The surface area and pore volume are $720 \mathrm{~m}^{2} / \mathrm{g}$ and $1.4 \mathrm{~cm}^{3} / \mathrm{g}$, respectively. Additional information about the aerogel structure was gathered by using small-angle X-ray scattering (SAXS). The analysis of the SAXS data indicates that the aerogel mass distribution is fractal, with a fractal dimension of 1.4. This small fractal dimension indicates a highly porous sol-gel network and is consistent with the fractal dimension of other aerogel materials. The size distribution of the particles that constitute the aerogel was also measured. Based on the Guinier analysis of the scattering data, the radius of gyration of the particles ranges from 14 to $80 \AA$. Both the nitrogen adsorption and the SAXS data for our aerogel agree well with those obtained for the aerogels synthesized by conventional protocols.

A possible mechanism for the aerogel formation in the ionic liquid may be formulated as follows. Formic acid initiates the formation of the sol particles, which effectively aggregate in the ionic liquid as a sol-gel network. Concurrently, the ionic liquid becomes entrapped in the growing covalent silica network, rather than being chemically bound to the inorganic matrix. A long aging time before extraction of the nonvolatile ionic liquid further enhances the stability of the aerogel network. No macroscopic phase separation between the gel and the ionic liquid solvent has been observed. The homogeneity of the material is retained throughout the entire aging process. This indicates that the interaction between the sol particles and the ionic liquids is favorable with respect to thermodynamic constraints. The ionic liquid forms a homogeneous solution with sol-gel precursors. If other solvents (e.g., dimethyl sulfoxide, water) are used in the sol-gel preparation, no appreciable pore volumes $\left(<0.1 \mathrm{~cm}^{3} / \mathrm{g}\right)$ are found. In fact, similar results have been reported in the literature concerning the doping of silica with organic liquids through sol-gel processes.

In conclusion, a silica aerogel has been synthesized using an ionic liquid as the reaction solvent. This technique allows aerogel synthesis under mild chemical conditions and eliminates the risky supercritical drying process. We expect that this new methodology can find applications in synthesizing new aerogels and aerogel films for separation, catalysis, and insulation.

\subsection{PUBLICATIONS}

S. Dai, Y. H. Ju, H. J. Gao, J. S. Lin, S. J. Pennycook, and C. E. Barnes, "Preparation of Silica Aerogel Using Ionic Liquids as Solvents," Chem. Comm., in press.

Y. H. Ju, O. F. Webb, S. Dai, J. S. Lin, and C. E. Barnes, "Synthesis and Characterization of Ordered Mesoporous Anion-Exchange Inorganic Hybrid Resins for Radionuclide Separation," Ind. Eng. Chem. Res., in press. 


\title{
5. PHYSICAL PROPERTIES RESEARCH
}

\author{
T. W. Schmidt
}

\subsection{PHYSICAL PROPERTY MEASUREMENTS OF PRODUCED WATER (D. A. Bostick, C. H. Mattus, and W. V. Steele)}

Contact: D. A. Bostick

Telehpone: (865) 576-7695

Internet: bostickda@ornl.gov
Contact: W. V. Steele

Telephone: (865) 576-7696

Internet: steelewv@ornl.gov

Summary: Members of the Petroleum Environmental Research Forum (PERF) met to finalize agreements on the specifics of oil and water sample selection and analytical protocol to identify their constituents. PERF members decided that four formation water samples from Gulf of Mexico oil platforms would be collected and forwarded to ORNL staff for analysis. The analyzed samples would then be used in testing methods to reduce the hydrocarbon content of the formation waters to meet environmental compliance criteria. Cost quotations are currently being received for the analysis of specific organic constituents requested by PERF.

\subsubsection{Purpose and Scope}

Soluble organics in produced water and refinery effluents are treatment problems for the petroleum industry. Production formations and refineries take special efforts to meet regulatory discharge requirements for dissolved organics. These problems are expected to increase as environmental regulations become stricter and production from deepwater operations increases. Deepwater crudes are more polar, which increases the amount of dissolved hydrocarbons in the produced water and refinery effluents. Early data from the Gulf of Mexico wells indicate that the dissolved hydrocarbons will increase significantly as deepwater production increases.

Neither the chemistry involved in the production of soluble organics in the petroleum industry nor the impact of these compounds on total effluent toxicity is well understood. Several industrial companies, including Shell, BP, Chevron, Phillips, Marathon, and Statoil, are developing a collaborative project to characterize and evaluate water solubles, aimed at reducing future production of these contaminants. This project will increase understanding of the production of water-soluble organics and will ultimately result in reduced production of water solubles and development of guidelines for effluent treatment. Quantitative characterization data are needed as the first step in this activity.

\subsubsection{Progress}

PERF members have requested a number of characterization parameters that will be used to develop a model for predicting the toxicity of produced water during drilling operations. For organic constituents these include (1) light aliphatic and aromatic gases and content, (2) semivolatile organics, (3) light organic acid analysis by ion chromatography or HPLC chromatography, (4) total recoverable hydrocarbon content, and (5) thiophene analysis by gas chromatography. Analyses of inorganics on formation water samples include (1) major and minor cation analysis by inductively coupled plasma (ICP) spectrometry, (2) major and minor anion analysis by ion chromatography, and (3) carbonate and bicarbonate analysis by titration. A summary of U.S. Environmental Protection Agency (EPA) methods has been submitted to PERF staff for approval as the analytical protocol for 
the required sample analyses. Analytical equipment is currently being located and set up in anticipation of sample receipt. Cost quotations are also being requested for organic analyses performed by off-site laboratories. Additionally, pressurized equipment is being acquired for the preparation of formation water simulant-crude oil samples at high pressure and temperature needed to estimate the organic content of deep-well-formation waters.

\section{BIOCHEMICAL ENGINEERING}

\section{B. H. Davison}

\subsection{GREEN BIOPOLYMERS FOR IMPROVED DECONTAMINATION OF METALS FROM SURFACES: SORPTIVE CHARACTERIZATION AND COATING PROPERTIES-EMSP (B. H. Davison, T. Kuritz, and C. K. McKeown)}

Contact: B. H. Davison

Telephone: (865) 576-8522

Internet: davisonbh@ornl.gov

Summary: The objective of the proposed Environmental Management Science Program (EMSP) research is to develop a fundamental understanding of important biological and physical chemical parameters for effective decontamination of metal surfaces using environmentally benign aqueous-based biopolymer solutions. Understanding how heavy metal-chelating biopolymers coat and interact with contaminated surfaces will benefit the development of novel, safe, easy-to-apply decontamination methodologies for removal of radionuclides and heavy metals.

\subsubsection{Research Objective}

The goal of the proposed research is to develop a fundamental understanding of important biological and physical chemical parameters for effective decontamination of metal surfaces using environmentally benign aqueous-based biopolymer solutions. Understanding how heavy metal-chelating biopolymers coat and interact with contaminated surfaces will benefit the development of novel, safe, easy-to-apply decontamination methodologies for the removal of radionuclides and heavy metals. The benefits of these methodologies will include the following:

- decreased exposure hazards for workers;

- decreased secondary waste generation;

- increased efficiency of decontamination;

- positive public appeal and development of novel, nature-friendly business opportunities; and

- lower cost of cleanup to the government.

We propose to use aqueous biopolymer solutions to coat a contaminated metal surface (i.e., steel), solubilize the heavy metals (e.g., uranium) from the surface, and bind the heavy metals into the biopolymer. The biopolymer coating (containing the immobilized hazardous metal contaminants) will then be removed as a viscous film, as a dry powder, or by washing. This "apply, wait, and remove" procedure will reduce the amount of worker time spent in decontamination activities. 


\subsubsection{Progress}

Biopolymers can coat surfaces and absorb metals from bulk solutions. Using copper ion sorption as a spectrophotometric screen, we showed that copper was sorbed by the biomass from the nitrate buffer onto a biopolymer coating on a glass slide. We propose to use aqueous biopolymer solutions to coat a contaminated metal surface (i.e., steel), solubilize the heavy metals (e.g., uranium) from the surface, and bind the heavy metals into the biopolymer. A technical challenge in the protocol development is determining quantitative numbers per gram of biopolymer as the biopolymers swell and sorb buffer ions as well as metal ions. We resolved this by careful mass balances. The use of copper ion as a quick spectrophotometric screen of metal sorption was determined to be unfeasible due to interfering compounds and the low levels of copper at equilibrium. Subsequently, we focused on the direct use of other metals (cadmium) and analysis by ICP.

We have generated biopolymers for metal sorption screening by cultivation of algae (cyanobacteria) in photobioreactors. Eight different algal strains were used and produced a large volume of biopolymers. The production of the biopolymer as the sorptive coating must be easy and inexpensive; therefore, we must use algae that are easy to cultivate.

Cadmium sorption isotherms were measured for biopolymers and biomass. Cadmium sorbed into the algal biomass. From the sorption isotherms, it was determined that the best biomass has a capacity of over $80 \mathrm{~g} \mathrm{Cd} / \mathrm{g}$ dry biomass, with an affinity constant below $1 \mathrm{mg} \mathrm{Cd} / \mathrm{g}$. This shows a good capacity from an inexpensive biosorbent. Cadmium was used as a model test compound for other heavy metals (specifically cesium, but also uranium) and analyzed by ICP. A low affinity constant is needed to allow removal of the trace amounts of contamination, while a good capacity is needed if bulk contamination is present. These figures suggest a capacity comparable with those of inorganic sorbents with a better affinity. We will extend these tests to uranium.

\subsubsection{Publication}

B. H. Davison, "Green Biopolymers for Decon of Contaminated Metal Surfaces" accepted for publication in the Proceedings of the 2nd Topical Meeting on Decommissioning, Decontamination and Reutilization, Knoxville, Tennessee, September 12-16, 1999.

\subsection{FUNDAMENTAL ENGINEERING FOR BIOFILTRATION-EMSP (J. W. Barton, K. T. Klasson, and B. H. Davison)}

Contact: J. W. Barton

Telephone: (865) 241-5706

Internet: bartonjw@ornl.gov

Summary: Biofiltration systems can be used for treatment of volatile organic compounds (VOCs); however, the systems are poorly understood and are currently operated as "black boxes." Common operational problems associated with biofilters include fouling, deactivation, and overgrowth, all of which make biofilters ineffective for continuous, long-term use. The objective of this investigation is to develop generic methods for long-term stable operation, in particular by using selective limitation of supplemental nutrients while maintaining high activity and the ability to regenerate biofilter activity. 


\subsubsection{Project Description}

Biofiltration systems can be used for treatment of VOCs; however, the systems are poorly understood and are currently operated as black boxes. Common operational problems associated with biofilters include fouling, deactivation, and overgrowth, all of which make biofilters ineffective for continuous, long-term use. The objective of this investigation is to develop generic methods for long-term stable operation, in particular by using selective limitation of supplemental nutrients while maintaining high activity and the ability to regenerate biofilter activity. As part of this effort, we will provide deeper fundamental understanding of the important biological and transport mechanisms in the biodestruction of sparingly soluble VOCs and will extend this engineering approach and developed mathematical models to two additional systems of high priority to the DOE Office of Environmental Management - direct degradation and cometabolic degradation of priority pollutants such as BTEX (benzene, toulene, ethylbenzene, xylene) and TCE (trichloroethylene), respectively.

\subsubsection{Progress}

We have measured fundamental solubilities of alkanes in biofilms and shown that they are fourfold higher than those reported and typically used for pure water. We have correlated these results in terms of partitioning between aqueous and biomass "phases." These results have been accepted for publication in Biotechnology and Bioengineering and will influence many degradative models.

Because trickling-bed biofilters have been historically operated as black boxes, we have developed a comprehensive two-dimensional predictive model to elucidate mass-transfer and kinetic. limitations in these systems. This model can be extended to a variety of columnar biofiltration systems by changing appropriate parameters. This user-friendly model/program can be installed and run independently on any IBM-compatible personal computer using Microsoft Windows 95/98.

We have isolated the VOC-degrading microorganism present in our trickle-bed consortium responsible for alkane uptake. By isolating the organism responsible, the reactor activity startup time is minimized. Cells can be grown and added directly to the reactor at startup to quickly populate the biofilter.

We have demonstrated noncometabolic degradation of a model-chlorinated organic (1-chloropentane) in an operating trickle-bed system. This work is unusual because most dechlorination processes require the presence of an additional substrate before degradation products of the target contaminant can be removed.

\subsection{DRY BIOCATALYSIS-LDRD (B. H. Davison, J. W. Barton, and T. Kurtiz)}

Contact: J. W. Barton

Telephone: (865) 241-5706

Internet: bartonjw@ornl.gov

Summary: In this research sponsored by Laboratory Director's Research and Development (LDRD) funding, we have hypothesized that enzymes that are capable of degrading certain VOCs could degrade these compounds more effectively by direct contact with the gaseous vapors. These "dry" enzymes, which exist in the absence of free water, should have reduced mass-transfer resistance. In addition, immobilized dry-state systems should possess additional thermostability and 
durability in comparison with their aqueous counterparts. We have begun examinations of three model systems to test our theories, as well as to identify, quantify, and qualify the parameters necessary for turning these theories into viable processes.

\subsubsection{Description}

We have hypothesized that enzymes that are capable of degrading certain VOCs could degrade these compounds more effectively by direct contact with the gaseous vapors. These "dry" enzymes, which exist in the absence of free water, should have reduced mass-transfer resistance. In addition, immobilized dry-state systems should possess additional thermostability and durability in comparison with their aqueous counterparts. We have begun examinations of three model systems to test our theories, as well as to identify, quantify, and qualify the parameters necessary for turning these theories into viable processes. In particular, we are testing dry-state enzymes for the removal/destruction of chemical warfare agents (CWAs) and VOCs, with some effort investigating this technique as an alternative means for producing commodity chemicals.

\subsubsection{Progress}

We have successfully expressed the enzyme, organophosphate hydrolase, on the membrane surface of a Gram-positive food bacterium for CWA simulant testing. The stable enzyme was also expressed in Escherichia coli bacteria.

Enzyme-impregnated fabric has been shown to react with methyl parathion vapors as they pass through the fabric from the interior. This results in the formation of a yellow breakdown product, indicating that the enzyme is working. These fabrics could potentially be used in clothing and in air filtration systems to remove CWAs from breathable air and, thus, prevent human exposure; the enzymes that are used in the dry state (without any water) could also be exploited for long-term decontamination of porous structures (e.g., the walls of buildings) if incorporated into latex paint-sealing in and subsequently destroying agents as they desorb.

Several different reactor schemes were used to investigate the effects of temperature and water activity (or relative humidity) on lipase-catalyzed gas-phase transesterifications. Lipase, a hydrolytic enzyme, was immobilized onto several supports with no free liquid and a controlled relative humidity and allowed to react with vapors of vinyl acetate and isoamyl alcohol, producing isoamyl acetate and acetaldehyde. This dry enzyme was observed to be stable for weeks - far longer than the aqueous lipase enzyme. In continuous tests at very low relative humidity, reaction rates increased with temperature up to $60^{\circ} \mathrm{C}$, yet retained some activity even at $90^{\circ} \mathrm{C}$. At higher relative humidity, however, the activity was destroyed. Data were obtained on the rates, stability, and competing reactions of this transesterification along with some data for another hydrolysis reaction. We observed complicating factors such as $\mathrm{pH}$ and sorption in the use of these dry solid enzymes to catalyze enzymatic reactions.

While examining by-products of methyl parathion degradation, we discovered a novel amino-based attack on these compounds by blue-green alga. These deaminated by-products have potentially less biotoxicity than those from other phosphate-based attacks. This degradative pathway also occurs with explosives such as trinitrotoluene (TNT). 


\title{
6.4 ENZYMATIC UPGRADING OF HEAVY CRUDES VIA PARTIAL OXIDATIONOR CONVERSION OF PAHs (A. P. Borole, E. N. Kaufman, B. H. Davison, P. Wang, C. L. Cheng, and J. M. Cosgrove)
}

\author{
Contact: A. P. Borole \\ Telephone: (865) 576-7421 \\ Internet: borolea@ornl.gov
}

Summary: The objective of this program is to develop new technologies for upgrading heavy oils by using novel enzyme-based bioprocessing concepts. Enzymes naturally occurring in aqueous environments will be adapted to work in organic media by chemical modification, making them stable and active in the organic media. Initial focus will be on oxidative reactions using hydrogen peroxide as an oxidant, converting polycyclic aromatic hydrocarbons (PAHs) into partially oxidized products. The work on this project was initiated in April 1999.

Literature review revealed enzymes from the peroxidase family and certain other hemecontaining proteins to be active towards PAH oxidation. Horseradish peroxidase was commercially available in a polyethylene glycol (PEG)-modified form and was, therefore, selected for initial testing. Cytochrome $\mathrm{c}$ was also selected based on literature reports showing its ability to partially oxidize PAH and organosulfur compounds. Initial work was focused on development of methods for quantitation of enzymes and proteins using standard assays, determination of protein solubility in organic and aqueous media, and analytical techniques for substrates (PAHs) and products using HPLC and gas chromatography. Cytochrome $c$ was shown to convert anthracene, 1methylanthracene, and 9-methylanthracene to the corresponding quinones and dibenzothiophene to the corresponding sulfone in aqueous media containing $10 \%$ acetonitrile.

We have initiated investigations into the modification of the protein cytochrome $c$. The modifications render hydrophobicity to the enzymes and make enzymes active in organic media. PEG was attached to cytochrome $c$ via a covalent linkage with the amine groups of the protein. Based on spectrophotometric measurements, it was predicted that approximately three PEG groups were attached to the protein. Additionally, based on the dry weight of the protein obtained after separation and lyophilization, it was inferred that a large amount of phosphate was bound to the protein in addition to the PEG groups. Activity of the modified protein is being evaluated in organic solvents.

\subsection{BIOLOGICAL DESULFURIZATION OF DIESEL AND PETROLEUM FEED- STOCKS (A. P. Borole, B. H. Davison, and C. L. Cheng)}

Contact: A. P. Borole

Telephone: (865) 576-7421

Internet: borolea@ornl.gov

Summary: The goal of this project is to investigate the biological desulfurization of a partially oxidized diesel fuel. Petro Star has provided ORNL with the oxidized fuel to investigate desulfurization in collaboration with Dr. E. Diaz, Consejo Superior de Investigaciones Cientificas (CSIC), Madrid, Spain.

Microbial biocatalysts engineered by CSIC were tested for desulfurization activity on dibenzothiophene sulfone as a model compound as well as the partially oxidized fuel provided by 
Petro Star. A Pseudomonas strain engineered with the genes for a reductase enzyme was demonstrated to have the highest rates of desulfurization and was chosen for further study. A preliminary experiment with the diesel fuel showed conversion of the major peaks in the sulfur chromatogram to desulfurized products.

\subsection{CHARACTERIZATION OF CHEMICALLY MODIFIED ENZYMES FOR BIOREMEDIATIONREACTIONS-EMSP (B.H.Davison,P. Wang,J.M.Cosgrove, and M. W. W. Adams")}

Contact: B. H. Davison

Telephone: (865) 576-8522

Internet: davisonbh@ornl.gov

Summary: The primary objective of the current work is to gain a fundamental understanding of the molecular and catalytic properties of enzymes that have been chemically modified so that they are catalytically active and chemically stable in organic solvents. The premise for this study is that stabilized and activated enzymes, which can function under harsh chemical conditions, are optimally suited for bioremediation in nonaqueous media where substrates of interest are more soluble and processed with greater efficiency.

\subsubsection{Research Objective}

Remediation processes frequently involve species possessing limited solubility in water. We are interested in novel strategies that use molecularly modified enzymes with enhanced activity and stability for the remediation of recalcitrant compounds in organic solvents. The performance of naturally occurring enzymes is usually quite limited in such organic environments. The primary objective of the current work is to gain a fundamental understanding of the molecular and catalytic properties of enzymes that have been chemically modified so that they are catalytically active and chemically stable in organic solvents. The premise for this study is that stabilized and activated enzymes, which can function under harsh chemical conditions, are optimally suited for bioremediation in nonaqueous media where substrates of interest are more soluble and processed with greater efficiency. This unique strategy is examined with respect to the degradation of chlorophenols and biphenyls polychlorinated (PCBs).

\subsubsection{Research Progress and Implications}

We are in the middle of the third year of a 3-year project, and this report summarizes work of the past year. We have obtained promising results both to demonstrate the proposed remediation strategy and to reveal fundamentals of the enzymatic catalysis in organic media. In one effort, ligninase (LiP) from Phanerochaete chrysosporium was modified with PEG and examined for the degradation of pentachlorophenol (PCP) in water-solvent mixtures. In another effort, basic catalytic behaviors of the chemically modified hyperthermophilic redox enzymes, including ferredoxin, hydrogenase, and aldehyde oxidoreductase, were examined in organic solvents.

*The University of Georgia. 


\subsubsection{PEG Modification of LiP and Its Bioremediation Applications}

LiP was modified using PEG to enhance its activity and stability for the biodegradation of PCP in the presence of acetonitrile (MeCN). MALDI-TOF-or matrix-assisted laser desorption/ionization-time-of-flight--mass spectrometry analysis showed that the modified enzyme has one or two PEG groups attached to each protein molecule. The modified enzyme retained $100 \%$ of its activity in aqueous solutions and showed enhanced activity in the organic solvent. The activity of the modified enzyme was found to be over twice that of the native enzyme in the presence of $10 \%$ $(\mathrm{v} / \mathrm{v}) \mathrm{MeCN}$. The solubility of PCP was enhanced significantly by the addition of $\mathrm{MeCN}$ to aqueous solutions. Capitalizing on the enhanced substrate solubility and the increased activity of the modified enzyme, the catalytic efficiency of the modified LiP in solutions containing $15 \%$ MeCN was over 11-fold higher than that of the native enzyme in aqueous solutions (from 44 to $480 \mathrm{~mol}$ PCP per mole of LiP per hour).

The degradation reaction products were examined. While tetrachlorobenzoquinone (TCBQ) was the only reaction product observed in previously reported papers, our work revealed the formation of three additional intermediates. This observation contributes to closing the mass balance between the yield of TCBQ and the disappearance of PCP. Furthermore, an additional product peak was observed by HPLC when PEG-LiP was used instead of the native enzyme. This result implies that the chemical modification of enzymes may affect the reaction specificity.

\subsubsection{Fundamentals of Modified Enzymes in Organic Solvents}

Focus is on the basic properties of a hyperthermophilic redox protein, ferredoxin (Fd) from Pyrococcus furiosus, in organic solvents. This study will contribute to our knowledge of the oxidation and reduction chemistry of biocatalytic systems placed in nonaqueous reaction media.

Thermal stability. Studies were carried out with native and PEG-modified Fd. Both enzymes dissolve in very polar organic solvents [e.g., dimethyl sulfoxide (DMSO)], whereas PEG-Fd was also soluble in much less polar solvents, including ethanol, propanol, butanol, benzene, and toluene. The thermal stability of both native and PEG-Fd is lower in DMSO compared with that in water $\left(t_{1 / 2}\right.$ at $80^{\circ} \mathrm{C}$ of 60 and $<10 \mathrm{~min}$, respectively). Nevertheless, PEG-Fd showed better stability in organic solvents. (The $t_{1 / 2}$ at $80^{\circ} \mathrm{C}$ increased to $30 \mathrm{~min}$ in toluene.)

Redox potential. The redox potentials of the native and $\mathrm{PEG}-\mathrm{Fds}$ were determined using cyclic voltammetry. In general, little difference in redox potential was observed between the native and modified enzyme, either in aqueous solution or in solvents such as DMSO. This indicates that the integrity of the iron-sulfur cluster was not altered by PEG modification. However, organic solvent appeared to be capable of dramatically altering the redox potential of the protein. The redox potential of Fd was measured to be $-690 \mathrm{mV}$ in DMSO, which is much lower than that in aqueous solution $(-390 \mathrm{mV}$ at $\mathrm{pH} 8)$. Since the absorption spectra of the protein remained intact in DMSO, the dramatic shift in redox potential is most likely due to the changes in cluster environment rather than structural variations. This was verified using a mutant Fd, D14S, in which a cluster-ligating aspartate is replaced by serine. The ability to change cluster potential may prove useful in allowing the kinetics of electron transfer during catalysis to be altered depending on the solvent that is used.

Protein interactions in organic solvents. The effect of the PEG modification on the ability of Fd to accept electrons in organic solvents from another enzyme, aldehyde ferredoxin oxidoreductase (AOR), was investigated. Information from such a study should be helpful in 
designing multienzyme redox systems to degrade recalcitrant organic pollutants. AOR oxidizes aldehydes to acids and directly reduces Fd. While there was no activity in aqueous solution when either one of the two proteins was modified with PEG (PEG-AOR or PEG-Fd), remarkably, a high rate of catalysis ( $50 \%$ the activity of the native proteins) was observed when both proteins were modified. However, no activity was detected with the two PEG-proteins in toluene or ethanol.

\subsubsection{Publications}

P. Wang, C. A. Woodward, and E. N. Kaufman, "Poly(ethylene glycol)-Modified Ligninase Enhances Pentachlorophenol Biodegradation in Water-Solvent Mixtures," Biotech. Bioeng., in press (1999).

C. Kim., C. A. Woodward, E. N. Kaufman, and M. W. W. Adams, "Stability and Sulfur Reduction Activity in Organic Media of Hydrogenase from the Hyperthermophilic Pyrococcus furiousus," Biotech. Bioeng., in press (1999).

P. Wang, E. N. Kaufman, C. Kim, and B. H. Davison, "Upon the Oxidation Reaction of Pentachlorophenol Catalyzed by Ligninase in the Presence of Hydrogen Peroxide," Appl. Microbiol. Biotechnol., in preparation (1999).

\subsection{SUCCINIC ACID PRODUCTION FROM LIGNOCELLULOSICHYDROLYSATES (N. P. Nghiem, B. H. Davison, C. K. McKeown, and R. D. Kirkegaard) \\ Contact: N. P. Nghiem \\ Telephone: (865) 574-1184 \\ Internet: nghiemnp@ornl.gov}

Summary: The objective of this project is to extend the previous research on the production of succinic acid from corn-derived glucose by adding the ability to metabolize xylose efficiently to an existing Escherichia coli strain and to test the value of this new capability for the production of succinic acid from industrial lignocellulosic hydrolysates. The project also addresses the development of an efficient biomass conversion process that incorporates rather than generates carbon dioxide.

The patented strain ATCC 202021 (AFP-111) was tested in a 1-L fermenter. This organism was able to utilize both glucose and xylose. However, the xylose utilization rates were much slower than those of glucose. An improved strain, AFP-X1, was obtained from Argonne National Laboratory and tested under conditions similar to those used for the original strain. The new strain showed significantly improved rates of xylose utilization when a synthetic solution containing both glucose and xylose was used. Actual hydrolysate obtained from Arkenol then was tested using a rich medium containing yeast extract and tryptone. Full-strength hydrolysate was found to inhibit succinic acid production. However, hydrolysate at $50 \%$ strength was found to support succinic acid production with complete xylose conversion. The yield of succinic acid was relatively low, $0.53 \mathrm{~g}$ succinic acid per gram of total sugar consumed. Future experiments will focus on succinic acid production from actual hydrolysate using an industrial medium containing light steep water as the nutrient source. The objective is to improve succinic acid yield and productivity. 


\subsection{ADVANCED REACTOR DESIGN FOR FUEL ETHANOL PRODUCTION (N. P. Nghiem, B. H. Davison, M. S. Krishnan, C. K. Shattuck, M. M. Blanco-Rivera, A. N. Jackson, and T. M. Cofer)}

Contact: N. P. Nghiem

Telephone: (865) 574-1184

Internet: nghiemnp@ornl.gov

Summary: The objective of this project is to develop and demonstrate advanced fermentation and separation systems for enhanced biofuel ethanol production that operate continuously and have high productivity, high yield, and good operability with reduced energy requirements. The feedstocks examined in this project include cornstarch, lignocellulosic hydrolysates, and gasified biomass.

Experiments on ethanol production from cornstarch using immobilized biocatalyst in a fluidized-bed bioreactor (FBR) were completed. The separate hydrolysis and fermentation (SHF) process was compared with the simultaneous saccharification and fermentation (SSF) process. Significantly higher substrate conversion and ethanol productivity were obtained with the SHF process since in this process it was possible to carry out the two conversion steps separately and at their widely different optimal conditions. In the SSF process, a compromise had to be made to accommodate both of these steps in a single reactor. The ethanol productivity obtained in an SHF process using dry-milled cornstarch as feedstock was almost ten times that of a typical ethanol batch fermentation process. An economic model was developed in collaboration with the U.S.Department of Agriculture Eastern Regional Research Laboratory. The model showed that an SHF process using the FBR technology would result in a savings of 3 cents per gallon of ethanol over a typical state-ofthe-art batch fermentation process. Therefore, the SHF process using the FBR will be advantageous for new ethanol plants.

Experiments on fuel ethanol production from lignocellulosic materials were initiated. A recombinant Zymomonas mobilis strain designated $\mathrm{CP} 4(\mathrm{pZB} 5$ ) was immobilized on $\kappa$-carrageenan beads and tested in the FBR using synthetic glucose-xylose mixtures at varied concentrations. Both glucose and xylose were effectively utilized by this strain. Ethanol productivity was five times greater than that obtained in batch reactors. However, the xylose-metabolizing capability of the immobilized cells in the FBR started to decline after 7 to 10 days. An improved strain designated ATCC31821(pZB5) was tested in the FBR under similar conditions. Stability of the xylosemetabolizing capability of this strain was extended to 14 to 18 days. Both strains of $Z$. mobilis showed $>90 \%$ of theoretical ethanol yield. A recombinant yeast, Saccharomyces 1400-LNHST, which was obtained from Purdue University, was tested in the FBR under the same conditions as those used for the two $Z$. mobilis strains. The xylose-metabolizing capability of the yeast strain started to decline after about 10 days. The ethanol yield obtained with the yeast strain also was lower than that obtained with the two $Z$. mobilis strains, mainly because of production of by-products such as glycerol and xylitol by the yeast strain. Further studies of the recombinant yeast strain in the FBR are in progress.

A new research area (i.e., development of a thermophilic ethanol-producing organism) was approved by DOE. This work will begin soon. 


\title{
7. SEPARATIONS AND MATERIALS SYNTHESIS
}

\author{
D. W. DePaoli \\ 7.1 CHEMICAL AND PHYSICAL PRINCIPLES IN MULTIPHASE SEPARATIONS \\ (D. W. DePaoli, V. F. de Almeida, C. Tsouris, D. D. Bruns, B. A. Grant, and S. U. \\ Sarnobat ) \\ Contact: D. W. DePaoli \\ Telephone: (865) 574-6817 \\ Internet: depaolidw@ornl.gov \\ Summary: Fundamental studies of multiphase systems, particularly those that explore \\ the use of electromagnetic fields to enhance transport processes, are continuing. Progress has \\ been made in several areas, including (1) spraying and mixing in electrohydrodynamic (EHD) \\ flows, (2) investigation of multiphase flows through experimental studies and high-performance \\ computing simulations, and (3) particle interactions under magnetic fields.
}

\subsubsection{Purpose and Scope}

This program, funded by the Office of Basic Energy Sciences, is comprised of several fundamental studies that explore transport processes in multiphase separations, with particular emphasis placed on the application of electromagnetic fields for enhancement. Experimental, theoretical, and computational methods are employed to investigate the effect of electromagnetic fields on transport processes in liquid-liquid, gas-liquid, and solid-liquid systems. This work will provide information necessary to devise novel means to dramatically improve transport rates in these systems, and thus will have widespread application to separations processes such as solvent extraction and distillation, as well as environmental and biotechnology areas.

\subsubsection{Progress}

\subsubsection{Electrohydrodynamic Spraying and Mixing}

We have shown that $\mathrm{EHD}$ mixing can be used for continuous, rapid production of homogeneous, ultrafine particles by sol-gel reactions. Because it provides efficient early-stage mixing, the EHD approach allows introduction of reactants in concentrated form, increasing initial nucleation rates and resulting in significantly smaller particles. Our findings are important because the prevailing approach in this field is to control product quality (size, morphology, homogeneity) strictly through chemistry. These experiments, performed with good mixing, indicate that the means of reactant introduction is a major controlling factor in product characteristics. Many previous studies in the literature will need to be reexamined in light of these results.

\subsubsection{Gas-Liquid Hydrodynamics in Macroporous Media}

Research work on the corrugated parallel plates apparatus continued. Observations of dry-air/distilled-water counterflow were made employing a high-speed video camera. Three distinct flow regimes were identified, providing new insight into the local flooding phenomenon and the complexity of phase interaction. A measure of mass transfer through relative humidity of 
the exiting air was associated with the observed flow regimes. It is concluded that local details of the flow do impact global mass transfer. Therefore, to develop realistic theoretical models, one must take the local complexity of the two-phase flow into consideration. Development of corresponding modeling tools proceeded with the improvement of existing lattice-Boltzmann methods. The shortcoming of employing a lattice to solve the Boltzmann equation has been theoretically circumvented so the continuum version of the equation can be solved in an arbitrary lattice; that is, no lattice periodicity is required. A novel approach to solve the Boltzmann equation has been developed in a form readily accessible to conventional discretization techniques. A preprocessor code has been devised to interface with finite-element programs available for the solution of conventional partial differential equations of hyperbolic type.

\subsubsection{Particle Interactions Under Magnetic Fields}

Studies of the aggregation of colloidal magnetic particles and the formation of chains were continued, with a focus on secondary-minimum aggregation and breakup of aggregates. A quantitative agreement between experiments and simulations was obtained for the transition from secondary- to primary-minimum aggregation. A paper entitled "Secondary Minimum Aggregation of Superparamagnetic Colloidal Particles" has been submitted for publication.

\subsection{NUCLEATION, GROWTH, AND TRANSPORT PHENOMENA IN HOMO- GENEOUS PRECIPITATION (M. Z-.C Hu, M. Shah, J. Thomas, K. Booth, and C. H. Byers)}

Contact: M. Z.-C. Hu

Telephone: (865) 574-8782

Internet: hum1@ornl.gov

Summary: The objective of this project is to develop an understanding of the nucleation and growth of clusters/particles involved in homogeneous or heterogeneous system related to advanced materials synthesis and processing.

\subsubsection{Purpose and Scope}

This research program, funded by the Office of Basic Energy Sciences, involves materials chemistry, synthesis, and fundamental studies of nucleation and growth phenomena in chemically reactive systems for synthesis of ultrafine (particularly nanosized), monodispersed particles (i.e., oxide ceramic precursor powders) and for solution deposition of ceramic films. A primary goal is the understanding of the mechanisms, kinetics, and thermodynamics of nucleation and particle growth under controlled sol-gel and wet-chemical processing conditions.

Our current focus in nanoscale/nanostructured materials research lies in the chemistry, reaction engineering, colloidal/interfacial sciences, and materials sciences in three major wetchemical systems: (1) homogeneous precipitation of nanospheres and microspheres in inorganic salt solutions of mixed solvent, (2) hydrothermal processing of inorganic salt aqueous solutions, (3) acid- or base-catalyzed hydrolysis and condensation of organometallic compounds (such as alkoxides) in water-alcohol solutions, and (4) ceramic film deposition onto self-assembled monolayers in solutions. Experiments utilize several specially developed techniques, including real-time dynamic light scattering (DLS), rapid-mixing flow cell coupled with FTIR and SAXS, 
as well as high-temperature X-ray diffraction (XRD), electron microscopy, Raman spectroscopy, and electrostatic spraying.

It is anticipated that the results of this work will have significant impacts upon the development of advanced materials such as nanoscale and nanophase ceramics that have dramatically improved properties over traditional "coarse-grained" ceramics. These advanced ceramics are potential candidates as structural ceramics, electroceramics, catalysts, nanocrystalline thin films, coatings, and nanostructured inorganic membranes.

\subsubsection{Progress}

Colorful titania films were successfully grown on bare silicon wafer surfaces via a novel nanocluster-design approach. Efforts were focused on improving the film surface roughness. Samples prepared by various deposition strategies will be characterized by atomic force microscopy and ellipsometry techniques. Meanwhile, films (titania and silica) on glass slides were studied by SAXS; data analysis is under way. Experiments were also carried out to test the feasibility of hydrothermally converting titania films to barium titanate films. Preliminary data by glancing-angle XRD showed that the films seem to have a certain preferred orientation; however, this needs to be confirmed by more sample studies.

\subsection{PHASE EQUILIBRIA MODIFICATION BY ELECTRIC FIELDS (C. Tsouris,} D. W. DePaoli, M. D. Dinsmore, J. Dong, N. B. Handagama, S. Z. Yiacoumi, and T.-Y. Ying)

Contact: C. Tsouris

Telephone: (865) 241-3246

Internet: tsourisc@ornl.gov

Summary: Fundamental studies are being undertaken that explore the use of electric fields to modify phase equilibria and enhance transport in multiphase separations processes. Experimental systems have been assembled and are currently used to investigate transport and thermodynamic effects of electric fields on vapor-liquid and liquid-liquid systems. Batchdistillation, vapor-liquid-equilibria, liquid-liquid-equilibria, and solid-liquid-equilibria experiments are in progress, using various liquid mixtures of polar-nonpolar, polar-polar, and nonpolar-nonpolar components. The results obtained to date show that electric fields have an effect on the vapor-liquid and solid-liquid equilibria of some systems and can be used to enhance mass transport in multiphase flows.

\subsubsection{Purpose and Scope}

The primary objective of this project, funded by the EMSP, is to enhance separations of mixtures by applying an electric field across an interface between two phases. Enhancement in separation may be caused either by increasing transport rates through the interface or by changing the phase equilibria. Electric fields have been known to interact with charge carriers, such as ions and electrons, leading to higher mass- and heat-transfer rates, fluid atomization, mixing, and pumping, which are transport effects. The effects of electric fields on the behavior of noncharged molecules and ions and the macroscopic thermodynamic behavior of the system are examined in this project. 


\subsubsection{Progress}

Experiments were conducted in which a stirred tank was used to form a liquid-liquid dispersion and an electric field was then applied with the objective of manipulating the properties of the dispersed and continuous phases. The effect of an electric field on the ambivalence region (i.e., the region in which either phase may be continuous or dispersed) was investigated. It was found that the ambivalence region is strongly modified by the electric. field to the point that by turning the field on and off, one may invert the phases back and forth. In addition, the drop size of the dispersed phase can be manipulated by applying a lower voltage than that needed for phase inversion. A patent application describing this effect has been submitted. Experiments of drop/drop and drop/interface coalescence were also conducted to better understand the physical mechanisms of the observed phenomena. A paper entitled "Phase Inversion of Liquid-Liquid Dispersions Under Applied Electric Fields" has been submitted for publication.

Solid-liquid-equilibria, or electrosorption, experiments were also continued to investigate the effect of electric fields on the separation of ions from aqueous solutions. Experiments are conducted to investigate both equilibrium and kinetic effects of electric fields. A model taking into account the overlapping of electrostatic double layers in pores has been developed. Modeling results are in agreement with experimental data of electrosorption capacity versus applied electric field.

\subsection{ELECTROSTATIC OZONATION (C. Tsouris, D. W. DePaoli, S. Yiacoumi, and W.-T. Shin)}

Contact: C. Tsouris

Telephone: (865) 241-3246

Internet: tsourisc@ornl.gov

Summary: Electric fields are used to form microbubbles containing ozone for the oxidation of organic pollutants in aqueous solutions. An experimental apparatus has been set up for (1) ozone generation from air or oxygen by means of corona discharge; (2) ozone spraying in an aqueous phase containing an organic solute, such as phenol, by inverse electrostatic spraying; and (3) collection of gas and liquid samples for chemical analysis. Experimental results showed an enhancement in the oxidation rate by electrostatically generated microbubbles, as compared with conventional bubble diffusers. Corona discharge caused at stronger electric fields was found to enhance oxidation.

\subsubsection{Purpose and Scope}

The primary objective of this project, funded by the Electric Power Research Institute, is to enhance the efficiency of ozonation processes by inverse electrostatic spraying. Ozone is a strong oxidant of organic molecules with fast reaction kinetics; thus, in most cases, ozonation is a mass-transfer-limited process that can be improved by decreasing the size of ozone-containing gas bubbles. Introduction of ozone in the form of microbubbles enhances the oxidation efficiency by (1) increasing the surface area per unit volume between the gas and liquid phases and (2) increasing the gas volume fraction (since smaller bubbles have a lower rise velocity than larger bubbles). This project is aimed at applying the knowledge gained in our fundamental studies of inverse electrostatic spraying to develop an efficient means for production of ozonecontaining microbubbles. 


\title{
7.4.2 Progress
}

Experiments including (1) mass transfer of ozone from the bubbles to deionized water, (2) oxidation of methylene blue dissolved in water, and (3) oxidation of phenol were continued. Results showed that radicals are formed in solution during electrostatic spraying of oxygen under electrical-discharge conditions; it was found that phenol and methylene blue are oxidized at accelerated rates. A model has been developed to describe phenol oxidation under electrical discharge. The model takes into account several possible plasma reactions occurring under corona discharge. The problem was found to be mathematically "stiff," requiring extremely small integration steps in order to provide correct results.

\subsection{OZONE TREATMENT OF SOLUBLE ORGANICS IN PRODUCED WATER (D. W. DePaoli, K. T. Klasson, C. Tsouris, and A. B. Walker )}

\author{
Contact: D. W. DePaoli \\ Telephone: (865) 574-6817 \\ Internet: depaolidw@ornl.gov
}

Summary: Studies have continued on the destruction of water-soluble organics from aqueous solutions similar to produced water. The results obtained to date have shown that it is possible to achieve suitable destruction with reasonable ozone loading and liquid residence time if mass-transfer limitations are overcome through the introduction of gas in the form of microbubbles.

\subsubsection{Purpose and Scope}

Oil production is shifting from "shallow" wells (water depth of $0-650 \mathrm{ft}$ ) to off-shore deepwater operations ( $>2600 \mathrm{ft}$ ). Production from these operations is now less than $20 \%$. By 2007 , it is projected that as much as $70 \%$ of the U.S. oil production will be from deepwater operations. The crude oil from these deep wells is more polar, increasing the amount of dissolved hydrocarbons in the produced water. Existing physical/chemical treatment technologies used to remove dispersed oil from produced water will not remove dissolved organics.

This project, funded by the Office of Fossil Energy, is aimed at devising compact, lowcost, efficient treatment processes to comply with current and future water quality regulations. It is an extension of previous research to improve the applicability of ozonation for treating organics and will help address the petroleum industry-wide problem of handling soluble organics from deepwater operations. The goal of this project is to maximize oxidation of water-soluble organics during a single-pass operation. The project investigates (1) oxidant production by electrochemical and sonochemical methods, (2) increasing the mass-transfer rate by forming microbubbles during ozone injection into the produced water, and (3) using ultraviolet irradiation to enhance the reaction if needed.

\subsubsection{Progress}

Results of limited continuous-flow tests of ozonation with simulated produced water have determined that (1) good removal efficiency is possible at reasonable residence times and ozone loading, (2) removal efficiency improves with longer residence time and larger ozone 
loading, and (3) performance improvement compared with previous work appears to be due to ozone injection in fine bubbles. We currently are conducting small-scale tests $(350-\mathrm{mL}$ reactor, $<10$-min residence time) concentrating on the introduction of fine bubbles through porous solids (glass and stainless steel frits). The course and scope of these studies will be reviewed in a meeting on October 7-8, 1999, with our industrial contacts on the PERF steering committee.

\subsection{ELECTRICALLY DRIVEN TECHNOLOGIES FOR RADIOACTIVE AEROSOL ABATEMENT (D. W. DePaoli, V. F. de Almeida, C. Tsouris, and C. Riahi-Nezhad)}

Contact: D. W. DePaoli

Telephone: (865) 574-6817

Internet: depaolidw@ornl.gov

Summary: Studies have been initiated in collaboration with the University of Texas to investigate the effects of electric and acoustic fields on the interactions of aerosol particles. Coupled experimental and computational methods are under development.

\subsubsection{Purpose and Scope}

The objective of this research program, funded by the EMSP and conducted in collaboration with $\mathrm{O}$. A. Ezekoye of the University of Texas at Austin, is to develop an improved understanding of how electrically driven processes (including electrocoalescence, acoustic agglomeration, and electric filtration) may be employed to efficiently treat problems caused by the formation of aerosols during DOE waste-treatment operations. The production of aerosols during treatment and retrieval operations in radioactive waste tanks presents significant problems related to cost, worker exposure, potential for release, and increased waste volume. Electrically driven technologies offer promise as remote methods for improved treatment; however, existing theoretical models are not suitable for performance prediction and design.

The basis for the project is the general fact that for most particulate collection technology, the marginal collection efficiency increases as the aerosol to be separated increases in size. We are investigating mechanisms for increasing the size of particles in an effluent stream as a preprocessing step. Our work is aimed at employing recent advances in theoretical approaches and experimental techniques to improve our understanding of how electrical and acoustic methods may be employed most efficiently alone or in tandem to tackle aerosol problems. The fundamental understanding achieved may provide the basis for developing innovative new approaches and optimizing removal processes.

\subsubsection{Progress}

An experimental apparatus is under construction. This apparatus will allow testing of the effect of electric and acoustic fields on flowing aerosols in a 10-cm (4-in.) square duct. In the planned experiments, size distribution and concentration of aerosol will be measured to determine the effectiveness of agglomeration. A laser-scattering device (Malvern Spraytec RTS5000) capable of real-time measurement of aerosol droplet size from 0.5 to $200 \mu \mathrm{m}$ and droplet concentration at aerosol densities up to $95 \%$ obscuration was evaluated very favorably during a demonstration at ORNL by the vendor; we plan to purchase a unit during the next quarter. 
Progress has also been made in the development of modeling tools capable of efficiently simulating the interactions of aerosols in applied fields. The approach being pursued is the improvement of existing lattice-Boltzmann methods. A novel technique to solve the Boltzmann equation has been developed in a form readily accessible to conventional discretization techniques. A preprocessor code has been devised to interface with finite-element programs available for the solution of conventional partial differential equations of hyperbolic type.

\title{
7.7 IMPROVED DECONTAMINATION: INTERFACIAL, TRANSPORT, AND CHEMICAL PROPERTIES OF AQUEOUS SURFACTANT CLEANERS (D. W. DePaoli, R. M. Counce, M. Z.-C. Hu, and A. W. Rowe)
}

\author{
Contact: D. W. DePaoli \\ Telephone: (865) 574-6817 \\ Internet: depaolidw@ornl.gov
}

Summary: Laboratory-scale experimentation is under way to determine improved means for decontamination using aqueous surfactant cleaners. Studies have shown that the removal of oil from metal surfaces is highly dependent on process conditions. In addition, we have found that through a simple modification of process conditions, we can greatly improve the speed of oil removal.

\subsubsection{Purpose and Scope}

This investigation, funded by the EMSP, is focused on decontamination using environmentally benign aqueous solutions, specifically the removal of organics and associated radionuclide and heavy-metal contaminants by surfactants. Aqueous-based solutions promise several advantages for decontamination processes, including low hazard potential, low cost, and reduced secondary waste volume through solvent recycle, solvent degradation, and/or incineration.

The work is aimed at gaining an understanding of interfacial, transport, and chemical processes that govern the effectiveness of aqueous-based surfactant solutions for decontamination of surfaces. In addition, efficient means for separation of waste materials from aqueous-based cleaners will be investigated. It is intended that the understanding developed in this work will be applied to decontamination/decommissioning tasks by performing laboratory tests on samples from contaminated DOE sites. These tests will provide the basis for developing improved approaches for removing organic contaminants.

\subsubsection{Progress}

Experiments on the effect of aqueous cleaning process conditions on the detachment of oil droplets from metal surfaces and the removal of oil films from metal coupons in a commercial sonicator bath have continued. Zeta potential measurements of oil droplets in surfactant solutions were also conducted. It appears these measurements may provide valuable information in determining the optimum solution $\mathrm{pH}$ for cleaning-surfactants leading to negative surface charge [CHAPS (defined in acronym list), Triton, and sodium dodecyl sulfate (SDS)] exhibited better cleaning at high $\mathrm{pH}$, while a surfactant leading to positive surface charge [cetyltrimethylammonium bromide $(\mathrm{CTAB})$ ] exhibited better cleaning at low $\mathrm{pH}$. 


\subsection{PUBLICATIONS}

S. Relle, S. B. Grant, and C. Tsouris, "Diffusional Coagulation of Superparamagnetic Particles in the Presence of an External Magnetic Field," Physica A 270, 427-43 (1999).

C. Tsouris and J. Dong, "Effects of Electric Fields on Phase Inversion of Liquid-Liquid Dispersions," Chem. Eng. Sci., accepted for publication (1999).

C. J. Chin, S. Yiacoumi, C. Tsouris, S. Relle, and S. B. Grant, "Secondary Minimum Aggregation of Superparamagnetic Colloidal Particles," Langmuir, submitted for publication (September 1999).

J. Dong and C. Tsouris, "Phase Inversion of Liquid-Liquid Dispersions Under Applied Electric Fields," Ind. Eng. Chem. Res., submitted for publication (September 1999).

\subsection{PRESENTATIONS}

D. W. DePaoli, C. Tsouris, and M. Z.-C. Hu, "Electrohydrodynamic Mixing and Reaction in Multiphase and Miscible Systems," MIXING XVII, Banff, Canada, August 15-20, 1999.

C. Tsouris, J. Dong, and D. W. DePaoli "Novel Phenomena in Liquid-Liquid Systems Under the Influence of Electric Fields," MIXING XVII, Banff, Canada, August 15-20, 1999.

C. Tsouris, D. W. DePaoli, W.-T. Shin, and S. Yiacoumi, "Electric-Field Effects on Fluids with Applications in Oxidation of Organic Compounds," MIXING XVII, Banff, Canada, August 15-20, 1999.

S. Yiacoumi, C. Tsouris, and D. W. DePaoli, "Novel Environmental Technologies Driven by Electric and Magnetic Fields," Association of Environmental Engineering and Science Professors (AEESP) Research Frontiers, Pennsylvania State University, University Park, Pennsylvania, July 31-August 3, 1999.

\subsection{PATENTS}

D. W. DePaoli and C. Tsouris, "Continuous Flow, Electrohydrodynamic Micromixing Apparatus and Methods," Attorney Docket: 12610-0390, ERID 0487, filed September 1999.

D. W. DePaoli, M. Z.-C. Hu, and C. Tsouris, "Method for the Production of Ultrafine Particles by Electrohydrodynamic Micromixing," Attorney Docket: 12610-0420, ERID 0645, filed September 1999.

M. Z.-C. Hu, "Photobiomolecular Deposition of Metallic Nanosized Clusters/Particles and Thin Films," ERID 0547, S-90,842, filed August 1999.

M. Z-C. Hu, "Sol-Gel Processing with Inorganic Metal Salt Precursors," ERID 0456, S-90,035, filed September 1999. 
M. Z.-C. Hu, "Methods for Producing Monodispersed Microsphere Particles of Barium Titanate," ERID 0473, S-90,054, filed September 1999.

C. Tsouris, D. W. DePaoli, and J. T. Shor, "A Method to Electrolytically Produce High-Purity Magnetite Powder," Application No. 09/371,638 (1999).

C. Tsouris and J. Dong, "Methods to Control Phase Inversions and Enhance Mass Transfer in Liquid-Liquid Dispersions," Application No. 09/397,281 (1999).

\section{FLUID STRUCTURES AND PROPERTIES}

\section{H. D. Cochran}

\subsection{INTERACTIONS OF SOLUTES, SOLVENTS, AND SURFACES (H. D. Cochran, H. J. Dai, H.-C. Li, and K. D. Heath) \\ Contact: H. D. Cochran \\ Telephone: (865) 574-6821 \\ Internet: cochranhdjr@ornl.gov}

Summary: Molecular-based studies performed on systems with supercritical solvents include X-ray and neutron-scattering experiments, molecular simulations, and integral equation theory to pursue fundamental understanding of how they behave in practical separations processes.

\subsubsection{Objective}

This program focuses on our fundamental interest in understanding the practical behavior of separation processes in terms of the underlying molecular interactions. Currently, the work focuses on systems with supercritical solvents and systems with surfactants that form micelles.

\subsubsection{Progress}

K. D. Heath has completed his Ph.D. dissertation on the fundamental study of aqueous dispersions in supercritical carbon dioxide. The droplet size of 10 vol \% aqueous ethanol dispersed by pulsed electric fields into supercritical carbon dioxide was found to correlate with the interfacial tension as temperature and pressure were varied. The rate of mass transfer of ethanol extracted from ethanol-water solution was found to be limited by equilibrium at carbon dioxide flow rates attainable in the present apparatus; thus, the rate of entrainment of droplets from the cell is negligible.

H.-C. $\mathrm{Li}$ has initiated efforts to develop and test interaction potential models for perfluoropolyethers. He has searched the literature for accurate vapor-liquid equilibrium and critical property data on model compounds. He has initiated ab initio calculations using Gaussian-98 to determine the distribution of electron charge density in molecules of the model compounds and to determine the potential energy as a function of rotation about the dihedral 
angle in the chain. Also, he has begun modifying an existing Gibbs ensemble Monte Carlo program for perfluoropolyethers.

8.2 MOLECULAR-BASED STUDY OF REVERSE MICELLES IN SUPERCRITICAL $\mathrm{CO}_{2}$ (P. T. Cummings, H. D. Cochran, Yu. B. Melnichenko, S. T. Cui, S. Salaniwal, H.-C. Li, and H.-J. Dai)

Contact: H. D. Cochran

Telephone: (865)574-6821

Internet: cochranhdjr@ornl.gov

Summary: This multi-institutional project aims to develop a molecular understanding of reverse micelles in supercritical carbon dioxide through small-angle scattering experiments and molecular simulation calculations and, in particular, to determine what molecular characteristics lead to successful surfactants for this application.

\subsubsection{Objective}

The aim of this multi-institutional project is to develop a molecular understanding of reverse micelles in supercritical carbon dioxide through small-angle scattering experiments and molecular simulation calculations and, in particular, to determine what molecular characteristics lead to successful surfactants for this application.

\subsubsection{Progress}

S. Salaniwal has focused molecular dynamics simulations of reverse micelles with aqueous cores in supercritical carbon dioxide on a system duplicating the temperature, pressure, and composition of a system previously studied by small-angle neutron scattering (SANS). The results are in approximate agreement with the experimental data.

Discussions with Professor Can Erkey of the University of Connecticut have led to plans for collaborative experimental research. Erkey's group has synthesized a novel surfactant, which has been shown in preliminary tests to support reverse micelles with aqueous cores in supercritical carbon dioxide. The surfactant is of a molecular structure that lends itself to molecular simulations. A small sample of the surfactant has been received from Erkey. H.-J. Dai and H.-C. Li are completing plans for SAXS and SANS experiments.

8.3 STRUCTURE AND PROPERTIES OF CHAIN MOLECULE SYSTEMS UNDER SHEAR (H. D. Cochran, P. T. Cummings, S.-T. Cui, H.-J. Dai, J. D. Moore, Yu. V. Kalyuzhyi, and M. D. Dadmun)

Contact: H. D. Cochran

Telephone: (865)574-6821

Internet: cochranhdjr@ornl.gov

Summary: This program employs experiments, molecular simulations, and theory to understand the structure and properties of systems of long-chain molecules under homogeneous shear (planar Couette flow). 


\subsubsection{Objective}

The aim of this program is to develop techniques for quantitative, molecular-based prediction of the structure and properties of systems of long-chain molecules undergoing shear flow through coarse graining of accurate, atomistic simulations of shorter-chain systems and coarse graining based on theory and verified by careful small-angle light scattering (SALS), SAXS, and SANS experiments on sheared systems.

\subsubsection{Progress}

H.-J. Dai is nearing completion of the assembly of the apparatus for SALS experiments of systems of chain molecules in shear flow at extreme strain rates. All of the major components are installed, and alignment of the optics is in progress.

J. D. Moore completed his Ph.D. research on molecular dynamics simulation of alkanes in shear flow. Manuscripts have been submitted for publication on the temperature dependence of viscosity of lubricant basestocks and on the steady-state and transient behavior of a shortchain polyethylene melt under shear.

S.-T. Cui has performed molecular dynamics simulations of dodecane narrowly confined between mica surfaces. His results have shown that the strong mica-dodecane interaction leads to increased dodecane density at constant normal pressure. No previous study has addressed this issue satisfactorily. At the higher-than-ambient density, the dodecane undergoes a structural transition as the spacing between mica surfaces is narrowed from eight to seven to six molecular layers. It changes dramatically from a liquid-like structure at eight layers to a nanocrystalline structure at six layers, ordered in the direction normal to the surfaces and in two orthogonal directions parallel to the surfaces. Stick-slip flow, a yield stress under a shear force, and other unusual properties inferred from experiments have been explained at a molecular level.

\subsection{PUBLICATIONS}

S. T. Cui, P. T. Cummings, and H. D. Cochran, "The Microscopic Origin of Solidification of Fluids Confined in Narrow Spacing," Nature, submitted (1999).

J. D. Moore, S. T. Cui, H. D. Cochran, and P. T. Cummings, "Rheology of Lubricant Basestocks: A Molecular Dynamics Study of $C_{30}$ Isomers," AIChE J., submitted (1999).

J. D. Moore, S. T. Cui, H. D. Cochran, and P. T. Cummings, "A Molecular Dynamics Study of a Short-Chain Polyethylene Melt. I. Transient Response," J. Non-Newt. Fluid Mech., submitted (1999).

J. D. Moore, S. T. Cui, H. D. Cochran, and P. T. Cummings, "A Molecular Dynamics Study of a Short-Chain Polyethylene Melt. II. Steady-State Shear," J. Non-Newt. Fluid Mech., submitted (1999).

H.-C. Li, V. M. Shah, and H. D. Cochran, "A Generalized Quartic Equation of State: Simplification and Extension to Mixtures," Sep. Sci. Technol., submitted (1999). 
K. D. Heath and H. D. Cochran, "Effects of Temperature and Pressure on Electrodispersion of Aqueous Droplets in Supercritical Carbon Dioxide," J. Supercrit. Fluids, submitted (1999).

K. D. Heath and H. D. Cochran, "Electrodispersion of Fine Aqueous Droplets in Supercritical Carbon Dioxide," Sep. Sci. Technol., submitted (1999).

J. D. Moore, S. T. Cui, H. D. Cochran, and P. T. Cummings, "The Transient Rheology of a Polyethylene Melt Under Shear," Phys. Rev. E, accepted (1999).

Y. B. Melnichenko, E. Kiran, K. Heath, S. Salaniwal, H. D. Cochran, M. Stamm, W. A. Van Hook, and G. D. Wignall, "SANS Studies of Polymers in Organic Solvents and Supercritical Fluids in Poor, Theta, and Good Solvent Domains," ACS Symp. Ser., in press (1999).

Yu. V. Kalyuzhnyi, S. T. Cui, P. T. Cummings, and H. D. Cochran, "Distribution Functions of a Simple Fluid Under Shear," Phys. Rev. E 60, 1716-723 (1999).

Y. B. Melnichenko, E. Kiran, G. D. Wignall, K. D. Heath, S. Salaniwal, H. D. Cochran, and M. Stamm, "Pressure and Temperature-Induced Transitions in Polymer Solutions in Supercritical Fluids," Macromolecules 32, 5344-347 (1999).

S. Salaniwal, S. T. Cui, P. T. Cummings, and H. D. Cochran, "Self-Assembly of Reverse Micelles with Aqueous Cores in Supercritical Carbon Dioxide via Molecular Simulation," Langmuir 15, 5188-192 (1999).

\section{BIOTECHNOLOGY RESEARCH}

\section{E. Greenbaum}

\subsection{KINETICS OF ENZYME-CATALYZED REACTIONS (E. Greenbaum, J. Woodward, J. W. Lee, B. R. Evans, and S. L. Blankinship)}

Contact: E. Greenbaum

Telephone: (865) 574-6835

Internet: greenbaume@ornl.gov

Summary: This quarterly report summarizes basic and applied research in the Biotechnology Research Group. Among the topic areas studied are photosynthesis research, molecular electronics, nanotechnology, nanofabrication, enzymology research for cellulose hydrolysis and hydrogen production, renewable hydrogen production by photosynthetic water splitting, and the development of fluorometric tissue-based biosensors.

\subsubsection{Purpose and Scope}

The purpose of this research program is to study the fundamental reactions of photosynthesis and conversion of light energy into chemical energy. Sustained simultaneous photoevolution of molecular hydrogen and oxygen is studied as a model photosynthetic reaction 
in which the energy-rich product is molecular hydrogen rather than a carbon dioxide fixation compound. Basic questions such as the molecular mechanisms of gas evolution, thermodynamic limits of photosynthesis, and the mininum number of light reactions that are required to split water into hydrogen and oxygen are studied. Fundamental studies on the enzymology of cellulase are also being performed.

\subsubsection{Progress}

We have immobilized Photosystem I (PSI) reaction centers on various nanostructures, including two parallel nanogaps, two terminal nanowires, and three terminal nanowires. The objective of these experiments is to determine whether differential selectivity exists between the various metal substrates. This selectivity is expected to be a useful property in orienting the reaction centers in nanogaps. Thus far, we have observed only a very slight selectivity of PSI on various metals. Further experiments will be performed in the Instrumentation and Controls Division to confirm this observation.

In studies on the recombinant cellulose-binding domain (CBD), the heme peptide mp-8 was attached to the recombinant $\mathrm{CBD}$ from Cellulomonas fimi cenA, using water-soluble carbodiimide. The mp8-CBD was able to oxidize tyrosine and 3-hydroxytyramine and to bind to cotton linters. The CBD contains an 8-histidine region for metal binding. Ferrous ion was complexed with the $C B D$, and the Fe-CBD was purified by gel filtration. The Fe-CBD was titrated with hydrogen peroxide. In studies on immobilized biocatalysts, it is interesting to note that dried propylene glycol-alginate bone gelatin spheres containing $\beta$-glucosidase from Aspergillus niger that had been stored at room temperature since 1992 were tested for their ability to hydrolyze cellobiose. A sample of these spheres was rehydrated and assayed. The activity levels found were unchanged from those published in 1992, indicating that the spheres have a shelf-life of greater than 7 years at room temperature.

\subsection{BIOMOLECULAR ELECTRONICS (E. Greenbaum, I. Lee, and J. W. Lee)}

Contact: E. Greenbaum

Telephone: (865) 574-6835

Internet: greenbaume@ornl.gov

Summary: This research project is focused on the construction of molecular electronic devices from components extracted from spinach membranes. The key molecular structure is the PSI reaction center, which is a molecular photovoltaic device and molecular diode.

\subsubsection{Purpose and Scope}

This research project is focused on the development of molecular optoelectronic devices. It is founded on knowledge of the intrinsic photophysical properties of the reaction centers of photosynthesis: nanometer dimensions, picosecond response times, and the ability to generate potential differences of about $1 \mathrm{~V}$ upon absorption of a photon. The research is based on original discoveries in molecular electronics made in the Chemical Technology Division at ORNL. These include (1) first demonstration of direct electrical contact with the electron transport chain of photosynthesis, (2) photoflash deposition of metallic platinum at the site of electron emergence from the PSI reaction center of photosynthesis, (3) establishment of a novel platinization "welding" technique that allows construction of two-dimensional arrays of PSI 
reaction centers on a metal surface, and (4) first demonstration of a biomolecular diode in a single isolated photosynthetic reaction center. Taken together, these results indicate that purified reaction centers of photosynthesis are very promising structures for the development of the next generation of optoelectronic devices.

\subsubsection{Progress}

We are developing a new technique to fill the channels of nanochannel glass with metal. This substrate forms multiple isolated conducting channels into which PSI reaction centers can be inserted, immobilized, and oriented. The goal is to make electrical contact with the inserted metal. Preliminary results demonstrate good conductivity of these metalized channels. Further work on improving the smoothness of the metal surface is under way. We have also constructed a real-time imaging device atop our atomic force microscope to investigate nanowire fabrication by electrolytic pulse deposition reactions. This setup is designed to enable us to observe nanodeposition of metal on nanowires in real time. Preliminary measurements are encouraging; however, some contamination was observed. Additional experiments are planned to address this issue.

\subsection{RENEWABLE HYDROGEN PRODUCTION BY PHOTOSYNTHETIC WATER SPLITTING (E. Greenbaum, J. W. Lee, and S. L. Blankinship)}

Contact: E. Greenbaum

Telephone: (865) 574-6835

Internet: greenbaume@ornl.gov

Summary: This mission-oriented research and development project is focused on the production of renewable hydrogen by microalgal water splitting.

\subsubsection{Purpose and Scope}

The purpose of this research program is the production of renewable hydrogen by photosynthetic water splitting. Experiments on the production of hydrogen and oxygen with a view towards the design and development of a real-world process system are being performed. An understanding of the limitations of the photosynthetic process, the light saturations curves, and the long-term stability and endurance of microalgae is being pursued.

\subsubsection{Progress}

We previously reported that Scenedesmus had better $\mathrm{O}_{2}$-evolving properties in pure hydrogen than did Chlamydomonas reinhardtii. This was incorrect. The reason $\mathrm{O}_{2}$ evolution was sustained in a pure $\mathrm{H}_{2}$ atmosphere was that nitrate was present in the growth medium used for Scenedesmus, whereas it was not present in that for Chlamydomonas. This allowed an alternate nitrate reductase pathway for Scenedesmus that was not present for Chlamydomonas. Nonetheless, these are still encouraging results, as the data for $C$. reinhardtii indicate. At $10 \%$ $\mathrm{H}_{2}$ in the carrier, about $75 \%$ of the pure helium rate is retained, and, at $100 \% \mathrm{H}_{2}, 10 \%$ is retained. These results go hand in hand with the oxygen-tolerant results reported in the last quarterly because a real-world chemical engineering process that employs photobiological reactors for the production of renewable hydrogen would preferentially work at elevated partial pressures of $\mathrm{H}_{2}$ and $\mathrm{O}_{2}$. The range of safe operation for hydrogen handling, even in air, is $4-75 \%$ by volume. 


\subsection{FLUOROMETRIC TISSUE-BASED BIOSENSORS (E. Greenbaum and C. A. Woodward)}

Contact: E. Greenbaum

Telephone: (865) 574-6835

Internet: greenbaume@ornl.gov

Summary: The objective of this research program is the utilization of microalgae as biosensors for the detection of environmental toxins.

\subsubsection{Purpose and Scope}

The purpose and scope of this research project are the development of rapid fluorometric assays for detecting environmental toxins, including chemical and biological warfare agents. It is based on the well-known fact that any interference with the electron transport chain of photosynthesis gives rise to an increase in the quantum yield of fluorescence. Moreover, the availability of relatively inexpensive commercial instrumentation makes this approach to detecting biological and chemical warfare agents a practical possibility.

\subsubsection{Progress}

Fluorometric tissue-based biosensors are being developed to provide a robust, rapid, and sensitive method for detecting levels of chemical toxins in the environment that may be immediately hazardous to human health. The light-sensitive pigments in photosynthetic tissue reaction centers display a fluorescence signature that is well characterized and directly related to the physical well-being of the tissue. Toxic chemical agents in a gas stream that contact the biosensor can quantitatively alter its fluorescence signal and quantum fluorescence yield. Cells of Nostoc commune, a drought-resistant cyanobacterium, have been immobilized on glass fiber filters. Their slow fluorescence patterns have been recorded using the OS30 fluorometer (OptiSciences) and the fast patterns using the OS1-FL modulated fluorometer (Opti-Sciences). The fluorescence yield in healthy cells is in the range of 0.3 for fast fluorescence and $0.5-0.65$ for slow fluorescence. A new cell chamber has been developed in which immobilized cells are exposed to a gas stream (flow rate of $25 \mathrm{~mL} / \mathrm{min}$ ) containing ultrapure air $/ 380 \mathrm{ppm} \mathrm{CO}_{2}$ and vapor of the vesicant simulants dibutylsulfide (DBS) and tributylamine (TBA). Reference tests are done in a gas stream of humidified air/ $/ \mathrm{CO}_{2}$ only. "Results show a decrease of $75-80 \%$ in quantum fluorescence yield (fast fluorescence) with 20-min exposure to DBS and TBA. The shift in yield is apparent with both compounds within the first $2 \mathrm{~min}$ of exposure. Slow fluorescence parameters show changes in the shape of the fluorescence signal without significant change in the overall quantum efficiency. Further experiments are under way to examine the effects of water stress on $N$. commune and to develop methods of maximizing the viability of the organism for use as a rugged biosensor that can be deployed in a variety of field situations.

\subsection{CELLULASES WITH ENHANCED ACTIVITY (B. R. Evans, J. Woodward, and Isabelle Hemery)}

Contact: J. Woodward

Telephone: (865) 574-6826

Internet: woodwardj@ornl.gov 
Summary: A thermophilic endoglucanase with high activity on soluble cellulose and two different CBDs were incubated with insoluble cellulose to determine if the endoglucanase would be able to bind to and hydrolyze insoluble cellulose by synergistic interaction with the CBDs. No hydrolysis of the insoluble cellulose was observed, indicating that the presence of the $\mathrm{CBDs}$ in the reaction was not sufficient to impart activity to the endoglucanase.

\subsubsection{Purpose and Scope}

To improve biocatalysts for industrial conversion of lignocellulosic materials into fermentable sugars, an increase in the catalytic rate of cellulose hydrolysis is targeted. The mechanisms of cellulase action on cellulose fibers and synergy between cellulases are still unclear. To resolve these problems, cellulases from both mesophilic and extremophilic microorganisms are being studied and their interactions with insoluble cellulose and cellulose fibers examined.

\subsubsection{Progress}

Studies are continuing on the purification of enzymes from psychrophilic bacteria from Arctic permafrost. Invertase from an Arctic permafrost strain was isolated and partially purified with ion-exchange chromatography. The $\beta$-glucosidase from the same strain was found to lose activity during purification attempts. Characterization of the $\beta$-glucosidase activity in crude cell extracts found that this enzyme is inhibited by sodium chloride at concentrations as low as $0.2 \mathrm{M}$. The effect of media formulation on $\beta$-glucosidase activity expressed by the psychrophile was investigated. Medium containing $0.19 M$ sodium chloride repressed expression of $\beta$ glucosidase.

\subsection{DEVELOPMENT OF A FUEL CELL (H. M. O'Neill and J. Woodward)}

Contact: J. Woodward

Telephone: (865) 574-6826

Internet: woodwardj@ornl.gov

Summary: Work is currently focused on methods to increase the efficiency of the enzymatic production of hydrogen from glucose.

\subsubsection{Purpose and Scope}

The future use of hydrogen as a renewable fuel is receiving widespread attention in both political and technical circles. An enzymatic in vitro process for the production of hydrogen from biomass is currently under investigation. This process centers on two NADP ${ }^{+}$-dependent enzymes, glucose dehydrogenase from Thermoplasma acidophilum and hydrogenase from Pyrococcus furious.

\subsubsection{Progress}

Investigation of hydrogen production in psychrophilic bacteria. These bacteria typically grow at low temperature $\left(0-25^{\circ} \mathrm{C}\right)$. Several cultures were obtained from the Environmental Sciences Division (ESD) at ORNL. They were isolated from marine and terrestrial environments. The marine cultures were designated 7-4, PV-1, and PV-2, and the terrestrial samples were designated AK29-B and Siberia 19. These are all pure cultures and are 
currently being typed by collaborators in the Environmental Sciences Division. The aim of this research is to investigate the production of biological hydrogen from whole bacterial cells.

The bacteria were cultivated under anaerobic conditions, and the amount of $\mathrm{H}_{2}$ that was produced was either monitored continuously or measured at set intervals. The growth conditions were varied for each organism to determine the optimal conditions for $\mathrm{H}_{2}$ production. Several different sugars (common monosaccharides and disaccharides) were used as carbon sources. The growth temperature $\left(4-25^{\circ} \mathrm{C}\right)$ was also varied. Different growth media, both minimal and rich, were tested. Only the bacteria that were isolated from marine environments produced $\mathrm{H}_{2}$. No $\mathrm{H}_{2}$ was detected in the bacteria isolated from terrestrial sources under any of the conditions tested. Although the bacteria had essentially finished growing after $24 \mathrm{~h}$, they continued to produce $\mathrm{H}_{2}$ for at least 1 week. The production of $\mathrm{H}_{2}$ was affected by the sugar source. For instance 7-4 produced the most $\mathrm{H}_{2}$ when grown with fructose as the carbon source. Similarly PV-1 and PV-2 utilized galactose and glucose most efficiently, respectively. The amount of glucose metabolized by culture 7-4 was compared with the amount of $\mathrm{H}_{2}$ produced after 3 days of growth. A yield of $0.8 \%$ was recorded based on a theoretical yield of $12 \mathrm{~mol} \mathrm{of} \mathrm{H}_{2}$ per mole of glucose. This suggests that it would be inefficient to use culture 7-4 directly for the production of $\mathrm{H}_{2}$.

These results are preliminary. Comparative analyses with organisms that grow at mesophilic $\left(25-45^{\circ} \mathrm{C}\right)$ and thermophilic temperatures $\left(45-100^{\circ} \mathrm{C}\right)$ are planned.

\subsection{HYDROGEN PRODUCTION FROM RENEWABLES (J. P. Getty and J. Woodward)}

Contact: J. Woodward

Telephone: (865) 574-6826

Internet: woodwardj@ornl.gov

Summary: Research has focused on the nonenzymatic production of hydrogen, specifically the optimization of hydrogen generation by an iron-powder catalyst under anaerobic conditions.

\subsubsection{Purpose and Scope}

The intent of this project is to identify a system of hydrogen generation for commercial vehicle transportation.

\subsubsection{Progress}

The continued analysis of hydrogen production using an iron-powder organic acid mixture has proven that the proposed mechanism is indeed exothermic in nature. In addition to theoretical hand calculations, the reaction was experimentally tested for accuracy. Data obtained indicate that the reaction is exothermic and self-sustaining for the duration of the reaction. The identification and effects of the proposed reaction by-products were also evaluated in the reaction vessel and with HPLC. Supportive theoretical calculations of the overall energy balance of the reaction are under investigation, and the results support the findings that more energy is released than was put into the reaction. Experiments are being repeated to confirm data reported and/or presented. 


\subsection{PUBLICATIONS}

J. Woodward, K. A. Cordray, R. J. Edmonston, M. Blanco-Rivera, S. M. Mattingly, and B. R. Evans, "Enzymatic Hydrogen Production: Conversion of Renewable Resources for Energy Production," Energy Fuels, accepted for publication.

V. A. Boichenko, E. Greenbaum, and M. Seibert, "Hydrogen Production by Photosynthetic Microorganisms," in Photoconversion of Solar Energy: Volume III: Molecular to Global Photosynthesis, ed. M. D. Archer and J. Barber, Imperial College Press, 1999, in press.

H. O'Neill and J. Woodward, "Nicotinamide Cofactors-Applications in Biotechnology," in Advances in Applied Biocatalysts, ed. B. C. Saha, ACS Symposium Book Series, submitted.

I. Lee, J. W. Lee, A. Stubna, and E. Greenbaum, "Measurement of Electrostatic Potentials Above Oriented Photosystem I Reaction Centers," submitted for publication (1999).

J. Woodward and S. M. Mattingly, "Method for the Enzymatic Production of Hydrogen," U.S. Patent 5,942,424, August 24, 1999.

J. P. Getty, J. Woodward, and M. T. Orr, "Continuous Hydrogen Production Using an Iron Catalyst Under Anaerobic Conditions," invention disclosure, submitted.

\subsection{PRESENTATIONS}

E. Greenbaum, J. W. Lee, and S. L. Blankinship, "Renewable Hydrogen Production by Photosynthetic Water Splitting," invited lecture presented at the Symposium on Hydrogen Production, Storage and Utilization, Annual Meeting of the American Chemical Society, New Orleans, Louisiana, August 23-26, 1999.

E. Greenbaum, I. Lee, and J. W. Lee, "Photosystem I Biomolecular Electronics," invited paper presented at the Symposium on Biosensors and Biomolecular Electronics, 1999 Joint International Meeting of the Electrochemical Society and the Electrochemical Society of Japan, Honolulu, Hawaii, October 17-22, 1999.

J. Woodward, "Continuous Hydrogen Production Using an Iron Catalyst Under Anaerobic Conditions,"presented at Argonne National Laboratory, July 27, 1999.

J. Woodward, "Utilization of Enzyme Biotechnology for Environmentally Friendly Energy Production and Control of Cellulosic Wastes," presented at the European Biological Control Laboratory, USDA-ARS, Montpellier, France, September 16, 1999. 


\title{
10. MOLECULAR STUDIES
}

\author{
P. T. Cummings
}

\subsection{AQUEOUS ELECTROLYTE SOLUTIONS AT AMBIENT AND SUPERCRITICAL CONDITIONS (P. T. Cummings, A. A. Chialvo, M. Predota, E. Yezdimer, and J. Rivera)}

Contact: P. T. Cummings

Telephone: (865) $241-4779$

Internet: cummingspt@ornl.gov

Summary: Simulations of supercooled water were continued and the temperature measured in different ways to probe nonergodicity. Gibbs ensemble and brute-force simulations were initiated to calculate the phase envelope of the Chialvo-Cummings polarizable model of water. A study on hydration of the alkanes in supercritical water was initiated.

\subsubsection{Purpose and Scope}

This project is aimed at developing microscopic-level understanding of aqueous electrolyte solutions using a combination of molecular simulation, statistical mechanical theory, and experimental measurement of vapor-liquid equilibrium and solution densities. The state conditions of interest range from ambient conditions to high-temperature/high-pressure supercritical conditions (such as those encountered in power plant steam cycles and supercritical water oxidation).

\subsubsection{Progress}

$A$ riel Chialvo analyzed the behavior of the configurational (translational and rotational) temperature in comparison with the corresponding kinetic temperature for supercooled water in the range of 75 to $150 \mathrm{~K}$, as part of an ongoing collaboration with P. G. Kusalik at Dalhousie University (Canada).

Eric Yezdimer initiated calculations of the free energy of solvation for a series of aqueous alkanes. A new, efficient method for calculating pressure dependencies for free energies of solvation, based on cumulant expansions, was developed. Ab initio studies using the ABC-FEP method of Wood et al. and Sakane et al. for the hydroxyl radical in bulk water were begun.

Milan Predota began production runs of a Gibbs ensemble Monte Carlo code for the calculation of vapor-liquid equilibrium of the Chialvo-Cummings polarizable model for water.

José Rivera, a new graduate student, began a brute-force molecular dynamics calculation of vapor-liquid equilibrium using the Chialvo-Cummings polarizable model for water. 


\subsection{THEORY AND MOLECULAR SIMULATION OF NONEQUILIBRIUM} SYSTEMS (P. T. Cummings, A. Baranyai, S. T. Cui, J. D. Moore, I. Borzsák, and C. McCabe)

Contact: P. T. Cummings

Telephone: (865) 241-4779

Internet: cummingspt@ornl.gov

Summary: A large-scale simulation of a model short-chain polyethylene $\left(\mathrm{C}_{100}\right)$ melt was continued, with emphasis on calculating transient rheological properties. Production runs of the viscosity of trioctylmethane at high pressure (around $1 \mathrm{GPa}$ ) were begun.

\subsubsection{Purpose and Scope}

In this project, we study and develop new simulation algorithms for systems away from equilibrium. These algorithms form the basis for the calculation of transport properties using nonequilibrium molecular dynamics.

\subsubsection{Progress}

Jonathan Moore continued work on the rheology of chain molecules under shear, focusing primarily on the transient and steady-state behavior of a model short-chain polyethylene $\left(\mathrm{C}_{100}\right)$ melt. He also completed and defended his $\mathrm{Ph} . \mathrm{D}$. thesis and is now employed in the molecular modeling group at Dow Chemical in Midland, Michigan.

Clare McCabe initiated production runs for calculating the viscosity of trioctylmethane at ambient and very high ( $\sim \mathrm{GPa})$ pressure. These are being performed on a new Beowulf cluster installed at The University of Tennessee.

\subsection{INTEGRAL EQUATION THEORIES OF MOLECULAR FLUIDS (P. $T$. Cummings, Yu. V. Kalyuzhnyi, and J. N. Herrera) \\ Contact: P. T. Cummings \\ Telephone: (865) 241-4779 \\ Internet: cummingspt@ornl.gov}

Summary: No progress was made on this project during the current quarter.

\subsubsection{Purpose and Scope}

This project involves the use of integral equation methods to describe molecular fluids and polymers in the dense-liquid regime. The emphasis is on analytically solvable integral equation theories.

\subsubsection{Progress}

No progress was made on this project during the current quarter. 


\subsection{MATHEMATICAL MODELING OF BACTERIAL MIGRATION THROUGH POROUS MEDIA WITH APPLICATION TO IN SITU BIOREMEDIATION (P. T. Cummings, R. M. Ford, ${ }^{*}$ K. C. Chen, ${ }^{*}$ and M. Jin ${ }^{*}$ )}

Contact: P. T. Cummings

Telephone: (865) 241-4779

Internet: cummingspt@ornl.gov

Summary: No progress was made on this project during the current quarter.

\subsubsection{Purpose and Scope}

This project is part of a broad effort at the University of Virginia funded by the IBM Environmental Research Program with Roseanne Ford and Peter Cummings as coprincipal investigators. The goal of the project is to perform experimental studies and computer simulations of bacterial motion in bulk aqueous phases and in porous media to develop an understanding of the transport processes involved in in situ bioremediation and to subsequently develop mathematical models for these processes. The project funding came to a close on December 31, 1997.

\subsubsection{Progress}

This project is no longer funded and is being concluded. A final report to the sponsors (IBM) was completed and submitted in October 1998. One manuscript remains outstanding.

\subsection{FUNDAMENTAL CHEMISTRY AND THERMODYNAMICS OF HYDRO- THERMAL OXIDATION PROCESSES (J. M. Simonson, R. E. Mesmer, D. J. Wesolowksi, P. T. Cummings, and A. A. Chialvo)}

Contact: P. T. Cummings

Telephone: (865) 241-4779

Internet: cummingspt@ornl.gov

Summary: The Chialvo-Cummings solvation formalism was applied to electrolyte solutions. Molecular simulation of $\mathrm{HCl}$ solutions was continued.

\subsubsection{Purpose and Scope}

The goal of the project is to use a combination of molecular theory/simulation and experimental measurements to develop a fundamental understanding of the thermophysical properties, phase equilibrium, and reaction processes involved in supercritical water oxidation (a new and promising technique for transforming hazardous organic waste).

\footnotetext{
"University of Virginia.
} 


\subsubsection{Progress}

Ariel Chialvo continued integral equation calculations of infinitely dilute alkali halides in a wider range of temperatures and molecular asymmetries to test a regression hypothesis currently used by experimentalists. Part of these calculations were presented at the 13th International Conference on the Properties of Water and Steam (Toronto, September 1999) and contained in the corresponding submitted manuscript.

\subsection{DEVELOPMENT AND APPLICATION OF FAST COMPUTATIONAL PROTEIN-FOLDING ALGORITHMS USING MASSIVELY PARALLEL SUPERCOMPUTERS (P. T. Cummings, P. H. LoCascio, K. Dill," and Kai Yue")}

Contact: P. T. Cummings

Telephone: (865) 241-4779

Internet: cummingspt@ornl.gov

Summary: Production runs were performed using our parallelized Geocore algorithm. A preproposal in response to DOE Office of Biological and Environmental Research solicitation LAB 99-19 was submitted and approved.

\subsubsection{Purpose and Scope}

The goal of the project is to develop parallel implementations of the Geocore ab initio exhaustive-search protein-folding algorithm. We use the parallel version to predict the structures of larger proteins; to improve the performance of the Geocore algorithm; and to develop much faster, less exhaustive algorithms for very large proteins.

\subsubsection{Progress}

Phil LoCascio conducted production runs with the parallelized Geocore ab initio proteinfolding algorithm. The project was renewed for a final year of LDRD funding. A search for a post-doctoral researcher was initiated. No publications were submitted, accepted, or published from this project during the current quarter.

10.7 MOLECULAR-BASED STUDY OF REVERSE MICELLES IN SUPERCRITICAL CARBON DIOXIDE FOR SOLVENT SUBSTITUTION IN THE U.S. CHEMICAL INDUSTRY (P. T. Cummings, H. D. Cochran, S. T. Cui, S. Salaniwal, G. Wignall, A Habenschuss, E. Beckman, ${ }^{\dagger}$ and J. deSimone ${ }^{\ddagger}$ )

Contact: P. T. Cummings

Telephone: (865) 241-4779

Internet: cummingspt@ornl.gov

\footnotetext{
"University of California-San Francisco.

University of Pittsburgh.

University of North Carolina.
} 
Summary: Production runs of our simulation code for reverse micelles were continued for a large-size system (five times larger than our previous simulations) and analyzed according to the Smoluchowski theory of aggregation dynamics.

\subsubsection{Purpose and Scope}

The aim of this project is to use SAXS and SANS techniques plus complementary molecular dynamics and Monte Carlo simulations to develop a molecular-level understanding of the formation and stability of reverse micelles in supercritical $\mathrm{CO}_{2}$. The results of this project will contribute to the fundamental knowledge base enabling the U.S. chemical industry to substitute supercritical $\mathrm{CO}_{2}$ for many of the toxic or hazardous solvents presently used in most industrial chemical reaction and separation processes. It is funded by the National Science Foundation and the EPA.

\subsubsection{Progress}

Sumeet Salaniwal performed production runs of our parallelized code for simulating water/surfactant $/ \mathrm{CO}_{2}$ systems for a large system that mimics the experimental conditions starting from two different initial configurations (ordered and scattered). The conditions of this simulation mimic the experimental conditions of a neutron-scattering study performed in the United Kingdom. Salaniwal investigated the effect of surfactant chemistry on aggregation dynamics and structure. He compared the simulation results with the Smoluchowski theory of aggregation dynamics.

\subsection{NANOTECHNOLOGY WITH EMPHASIS ON TRIBOLOGY: A COMBINED EXPERIMENTAL AND SIMULATION STUDY (P. T. Cummings, H. D. Cochran, S. T. Cui, C. McCabe, S. Granick, and G. Grest ${ }^{\dagger}$ )}

Contact: P. T. Cummings

Telephone: (865) 241-4779

Internet: cummingspt@ornl.gov

Summary: Production runs of the viscosity of perfluorobutane were performed. Molecular dynamics simulations of alkanes confined to nanoscale gaps were continued.

\subsubsection{Purpose and Scope}

The aim of the project, supported by the National Science Foundation through the interdisciplinary nanotechnology program, is to undertake a fundamental study of lubrication at nanometer scale, including experiments with surface rheometry and nonequilibrium molecular dynamics simulation. The goals of the research are to achieve overlap in shear rate between experiments and simulations with the same systems; extend both the experimental and computational efforts to more complicated systems and surface characteristics (including surfaces with chemical and topographical heterogeneity); and study not only the steady-state

*University of Illinois.

${ }^{\dagger}$ Sandia National Laboratory. 
shear response of nanotribology systems but also their transient behavior, including the technologically important issues related to adhesion.

\subsubsection{Progress}

Clare McCabe performed production runs of the viscosity of perfluorobutane using the potential model of Cui et al. at $200 \mathrm{~K}$ and $1.82 \mathrm{~g} / \mathrm{cm}^{3}$ ). The equilibrium perfluorobutane results will be compared with those from neutron scattering, hence testing the validity of the potential model. The perflouroalkane simulations mark the first step towards simulation of perfluoropolyether lubricants.

Shengting Cui continued molecular dynamics simulations of alkane liquids confined to nanoscale gaps between surfaces that mimicked the properties of mica. His simulations are unique in that the mica surfaces are pulled at a constant force, and the stick-slip behavior induced is then converted to a relative velocity of the surfaces. The results are being prepared for publication.

\subsection{OTHER IMPORTANT ACTIVITIES}

Peter Cummings was a visiting professor in the Department of Mathematics at the University of Melbourne for the period July 15 to August 15, 1999. The purpose of the visit was to work on the Web-based molecular simulation textbook and to give presentations at universities in Australia. Cummings continued his involvement in the interagency effort to establish a new national research initiative in nanoscale science and technology. This included giving an invited presentation at the U.S.-Swiss National Science Foundation Forum on Nanoscience and Nanotechnology in Zurich, Switzerland, in September. Also in September, Cummings participated in the first part of the International Comparative Study on Applying Molecular and Materials Modeling (http://www.itri.loyola.edu/molmodel/welcome.htm), sponsored by six federal research agencies. This involved site visits to 18 European companies and government laboratories.

\subsection{PUBLICATIONS}

\subsubsection{Submitted}

A. Baranyai and P. T. Cummings, "Towards a Computational Chemical Potential for Nonequilibrium Steady State Systems," Phys. Rev. E. (1999).

J. D. Moore, S. T. Cui, H. D. Cochran, and P. T. Cummings, "Rheology of Lubricant Basestocks: A Molecular Dynamics Study of $\mathrm{C}_{30}$ Isomers," AIChE J. (1999).

J. D. Moore, S. T. Cui, H. D. Cochran, and P. T. Cummings, "Molecular Dynamics Study of a Short-Chain Polyethylene Melt. I. Steady-State Shear," J. Non-Newt. Fluid Mech. (1999).

J. D. Moore, S. T. Cui, H. D. Cochran, and P. T. Cummings, "Molecular Dynamics Study of a Short-Chain Polyethylene Melt. II. Transient Response Upon Onset Shear," J. Non-Newt. Fluid Mech. (1999). 
A. A. Chialvo, P. G. Kusalik, P. T. Cummings, J. M. Simonson, and R. E. Mesmer, Molecular Approach to High-Temperature Solvation: Formal, Integral Equation, and Experimental Results," J. Phys.: Condens. Matter (1999).

A. A.Chialvo, P. G. Kusalik, Yu. V. Kalyuzhnyi, and P. T. Cummings, "Integral Equations Calculations to High-Temperature Solvation Phenomena," J. Stat. Phys. (1999) [Invited paper in issue honoring George Stell].

A. A. Chialvo, P. G. Kusalik, P. T. Cummings, J. M. Simonson, and R. E. Mesmer, "HighTemperature Solvation in Aqueous Electrolyte Solutions: Formal, Integral Equation, and Experimental Results," in Proceedings of the 13th International Conference on the Properties of Water and Steam (1999).

A. A. Chialvo, P. T. Cummings, J. M. Simonson, and R. E. Mesmer, "Ion Association in HighTemperature Aqueous HCl Solutions: A Molecular Simulation Study," in Proceedings of the 13th International Conference on the Properties of Water and Steam (1999).

S. Sakane, E. M. Yezdimer, J. Barriocanal, D. J. Doren, and R. H. Wood, J. Chem. Phys. (1999).

\subsubsection{Accepted}

A. Baranyai and P. T. Cummings, "Towards a Computational Chemical Potential for Nonequilibrium Steady State Systems," Phys. Rev. E. (1999).

S. H. Lee and P. T. Cummings, "Molecular Dynamics Simulation of Limiting Conductances for $\mathrm{LiCl}, \mathrm{NaBr}$, and CsBr in Supercritical Water," J. Chem. Phys. (1999). -

J. D. Moore, S. T. Cui, P. T. Cummings, and H. D. Cochran, "The Transient Rheology of a Polyethylene Melt Under Shear," Phys. Rev. E. (1999).

A. A. Chialvo, P. T. Cummings, J. M. Simonson, and R. E. Mesmer, "Solvation in HighTemperature Electrolyte Solutions," J. Mol. Liq. (1998).

E. J. M. Filipe, E. J. S. Gomes de Azevedo, L. F. G. Martins, V. A. M. Soares, J. C. G. Calado, C. McCabe, and G. Jackson, "Thermodynamics of Liquid Mixtures of Xenon and the Alkanes: Xenon + Ethane and Xenon + Propane," J. Phys. Chem. (1999).

E. J. M. Filipe, L. F. G. Martins, J. C. G. Calado, C. McCabe, and G. Jackson, "Thermodynamics of Liquid Mixtures of Xenon and the Alkanes: Xenon $+\mathrm{N}$-Butane and Xenon $+\mathrm{I}-$ Butane," J. Phys. Chem. (1999).

\subsubsection{Published}

S. T. Cui, H. D. Cochran, and P. T. Cummings, "Vapor-Liquid Phase Coexistence of Alkane-CO and Perfluoroalkane-CO ${ }_{2}$ Mixtures," J. Phys. Chem. B 103, 4485-4491 (1999).

Y. Kalyuzhnyi, S. T. Cui, P. T. Cummings, and H. D. Cochran, "Distribution Functions of a Simple Fluid Under Shear. I. Low Shear Rates," Phys. Rev. E. 60, 1716-1723 (1999). 
T. Driesner, T. M. Seward, and I. G. Tironi, "Molecular Dynamics Simulation Study of Ionic Hydration and Ion Association in Dilute and 1 Molal Aqueous Sodium Chloride Solutions from Ambient to Supercritical Conditions," Geochim. Cosmochim. Acta 62 , 3095-3107 (1998).

T. Driesner and T. M. Seward, "An Empirical Method for the Determination of Single Ion Hydrogen Isotope Salt Effects in Aqueous Electrolyte Solutions," Chem. Geol. (Iso. Geosci. Sect.) 153, 281-287 (1999).

S. T. Cui, P. T. Cummings, and H. D. Cochran, "Molecular Dynamics Simulation of the Rheological Properties of a Model Alkane Fluid Under Confinement," J. Chem. Phys. 111, 1273-1280 (1999).

S. Salaniwal, S. T. Cui, P. T. Cummings, and H. D. Cochran, "Self-Assembly of Reverse Micelles in Water/Surfactant/Carbon Dioxide Systems by Molecular Simulation," Langmuir 15, 5188-5192 (1999).

T. Driesner and P. T. Cummings, "Molecular Simulation of the Temperature- and DensityDependence of Ionic Hydration in Aqueous $\mathrm{SrCl}_{2}$ Solutions Using Rigid and Flexible Water Models," J. Chem. Phys. 111, 5141-5149 (1999).

\subsection{PRESENTATIONS}

\subsubsection{Invited Seminars}

P. T. Cummings, "Visualizing Complex Physical and Chemical Phenomena at the Molecular Level," presented at the School of Information Technology, Swinburne Institute of Technology, Melbourne, Australia, July 29, 1999.

P. T. Cummings, "Molecular Simulation of the Formation of Reversed Micelles in Supercritical Carbon Dioxide," presented at the Research School of Chemistry, Australian National University, Canberra, Australia, August 3, 1999.

P. T. Cummings, "Molecular Simulation of the Formation of Reversed Micelles in Supercritical Carbon Dioxide," presented at the Department of Chemical Engineering, University of Melbourne, Melbourne, Australia, August 5, 1999.

P. T. Cummings, "Molecular Simulation of Lubricants Confined to Nanoscale Gaps," presented at the Department of Mathematics, University of Melbourne, Melbourne, Australia, August 11, 1999.

P. T. Cummings, "Molecular Simulation of Lubricants Confined to Nanoscale Gaps," presented at the Department of Applied Physics, Royal Melbourne Institute of Technology, Melbourne, Australia, August 12, 1999.

P. T. Cummings, "Molecular Simulation of Complex Systems Using Massively Parallel Supercomputers," presented at the Department of Materials and Applied Chemistry, Nihon University, Tokyo, Japan, September 29, 1999. 


\subsubsection{Invited Conferences}

P. T. Cummings, "Molecular-Based Modeling and Simulation of Nanoscale Systems," presented at the Swiss-U.S.-Forum on Nanoscience and Nanotechnology, Zurich, Switzerland, September 20-22, 1999.

P. T. Cummings, "Molecular Simulation of the Rheology of Lubricant Components Using Massively Parallel Supercomputers," presented at the Annual Meeting of the Society of Chemical Engineering of Japan, Kanazawa, Japan, September 27-29, 1999.

C. McCabe, "Phase Behavior of Chain Molecules Using the Saft-vr Approach," presented at the XII School on Complex Fluids, San Luis Potosi, Mexico, August 30-September 1, 1999.

\subsubsection{Contributed Conferences}

A. A. Chialvo, P. G. Kusalik, P. T. Cummings, J. M. Simonson, and R. E. Mesmer, "Molecular Approach to High-Temperature Solvation. Formal, Integral Equation, and Experimental Results," presented at the IV Liquid Matter Conference, Granada, Spain, July 3-7, 1999.

S. Salaniwal, H. D. Cochran, and P. T. Cummings, "Molecular Dynamics Simulation of Reverse Micelles of Di-Chain Surfactant with Aqueous Cores in Carbon Dioxide," presented at the IV Liquid Matter Conference, Granada, Spain, July 3-7, 1999.

S. Cui, H. D. Cochran, and P. T. Cummings, "Dynamical and Rheological Properties of Alkanes Confined in Nanometer Spacing," presented at the IV Liquid Matter Conference, Granada, Spain, July 3-7, 1999.

I. Borzsák, P. T. Cummings, and D. J. Evans, "Viscosity Calculations in Molecular Dynamics Simulations Using the Transient Time Correlation Function Formalism," presented at the IV Liquid Matter Conference, Granada, Spain, July 3-7, 1999.

J. D. Moore, S. Cui, H. D. Cochran, and P. T. Cummings, "The Transient Rheology of a Polyethylene Melt Under Shear," presented at the IV Liquid Matter Conference, Granada, Spain, July 3-7, 1999.

A. A. Chialvo, P. G. Kusalik, P. T. Cummings, J. M. Simonson, and R. E. Mesmer, "HighTemperature Solvation in Aqueous Electrolyte Solutions: Formal, Integral Equation, and Experimental Results," presented at the 13th International Conference on the Properties of Water and Steam, Toronto, Canada, September 12-16, 1999.

A. A. Chialvo, P. T. Cummings, J. M. Simonson, and R. E. Mesmer, "Ion Association in HighTemperature Aqueous $\mathrm{HCl}$ Solutions: A Molecular Simulation Study," presented at the 13th International Conference on the Properties of Water and Steam, Toronto, Canada, September 12-16, 1999. 
$-$

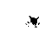




\section{INTERNAL DISTRIBUTION}

1. J. M. Begovich

2. E. D. Collins

3. L. D. Duncan

4. R. G. Gilliland

5-60. B. J. Johnson

61. T. R. Jones

62-63. R. T. Jubin

64. J. A. Klein

65. L. E. McNeese

66. G. E. Michaels

67. B. D. Patton

68. S. M. Robinson

69. M. K. Savage

70. R. M. Wham

71. ORNL Laboratory Records-RC

72. Central Research Library

73-74. ORNL Laboratory Records-OSTI 
